\title{
Radioimmunotherapy of human tumours
}

\author{
Steven M. Larson, M.D., \\ 417 East $68^{\text {th }}$ Street, New York, NY USA 10065 \\ Jorge A. Carrasquillo, M.D., \\ 1250 First Avenue, New York, NY USA 10065 \\ Nai-Kong V. Cheung, M.D., PhD*, and \\ 417 East $68^{\text {th }}$ Street, New York, NY USA 10065 \\ Oliver Press, M.D., Ph.D. \\ Fred Hutchinson Cancer Research Center, 1100 Fairview Avenue, North, P.O. Box 19024, \\ Seattle, WA USA 98109
}

\section{PREFACE}

Eradication of cancer remains a vexing problem despite recent advances in our understanding of the molecular basis of neoplasia. One therapeutic approach that has demonstrated potential involves the selective targeting of radionuclides to cancer-associated cell surface antigens using monoclonal antibodies. Such radioimmunotherapy (RIT) permits the delivery of a high dose of therapeutic radiation to cancer cells, while minimizing the exposure of normal cells. Although this approach has been investigated for several decades, the cumulative advances in cancer biology, antibody engineering, and radiochemistry in the last decade has markedly enhanced the ability of RIT to produce durable remissions of multiple cancer types.

\section{ToC blurb}

The modern manufacture of tumor-selective antibodies bearing tumor-killing radioactive cargo has effectively harnessed the power of the atom to safely destroy cancer cells. This review presents fundamental concepts of chemistry, physics, and biology essential for effective radioimmunotherapy of human cancer.

\footnotetext{
Radioimmunotherapy (RIT) exploits the immune protein as a carrier for radioactivity, as a tracer or targeted therapeutic. The radioantibody is formulated as a drug in sterile and pyrogen-free form and intravenously injected directly into the tumour, or compartmentally into a body cavity such as the peritoneum, pleura, or intrathecal space. Once injected, the radioantibody is distributed by blood flow, diffusion, or convection to its natural target: an antigen-binding site on tumour cells. The radioactive cargo, in the form of a radionuclide that emits therapeutic quantities of particulate radiation, delivers the tumouricidal dose to the tumour mass. The radiation effects are due to the enormous energy release that occurs
}

\footnotetext{
Corresponding author: larsons@ mskcc.org. *oint Senior Authors

There is NO Competing Interest.
} 
during radioactive decay, and the process is one of the most energy-efficient known. For example, a tumouricidal radiation dose of $10,000 \mathrm{cGy}$ requires $\sim 6$ picomoles per gram of the high-energy beta emitter yttrium-90.

Clinically, RIT is most widely applied to the most radiosensitive tumours, namely leukemias and lymphomas. Solid tumours are more radioresistant, requiring about 5-10 times the deposited radiation doses for objective tumour response. The relative radiosensitivity or radioresistance is an intrinsic property of the cancer cell and correlates best with the cell of origin of the tumour. The more radiosensitive normal tissue, such as haematological system, give rise to tumours that tend to be considerably more radiosensitive; conversely, the more radiation-resistant tissues, such as brain or bronchial epithelium, give rise to more radioresistant tumours. Additional factors increasing radiation resistance include hypoxia and the ability to rapidly repair radiation-induced damage ${ }^{1}$.

Regardless of intrinsic radiosensitivity, the goal for RIT is to safely deliver a high-radiation dose to a tumour. One way to achieve this is by choosing situations where the tumour is confined in an accessible body cavity or space, resulting in less dilution of the radioantibody as it homes in on its cancer-associated antigen target. Pediatric solid tumours such as central nervous system (CNS) metastases of neuroblastoma have shown excellent responses after intrathecal administration of therapeutic amounts of a radioantibody. For the common solid tumours, such as those in the pancreas, melanoma, prostate, and colon, direct intravenous injection of a radioantibody has been relatively unsuccessful.

A more recent advance in RIT has been the development of quantitative methods for estimating the radiation-absorbed dose for human use, both for tumour tissue and normal tissue, as a basis for individualizing patient treatment and avoiding toxicity associated with excessive radiation exposure. The fundamental concept is an example of a 'theranostics' approach, in which the same reagent serves both a diagnostic and therapeutic purpose; for example, the same radioisotope used in tracer quantities for diagnosis is followed by simple scale-up to larger amounts to achieve a therapeutic effect. Although in principle, any nuclear imaging method may be used in theranostic approaches for RIT, the use of quantitative highresolution positron emission tomography (PET)/computed tomography (CT) imaging of antibodies provides precise dosimetry to refine staging information that will improve patient selection and treatment planning as a prelude to effective treatment. [Box 1]

\section{Box 1}

\section{Dosimetry: Estimating radiation deposited in tumours and normal tissue from radioimmunotherapy}

Radiation effects on biological tissues are caused by the energy emitted by radioactive decay that is deposited in tissues. For radioimmunotherapy (RIT) we are most concerned with radioisotopes, which decay with particulate and non-penetrating radiations such as alpha particles, beta particles, auger, or low-energy X-rays. Since not all components of tissues and cells are equally sensitive, the site of deposition of the radiation energy is also important, as is the distance over which the radiation energy is deposited at the tissue level, often referred to as linear energy transfer. 
Internal radiation doses are computed by an established set of equations that convert the energy deposited in tissue into units of radiation-absorbed dose (rad) or centigray (cGy). The Committee on Medical Internal Radiation Dosimetry (MIRD) has developed a phantom validated approach that is most applicable to normal organs. This has been adopted by the FDA as a basis for estimating radiation doses to whole normal organs.

Because organs comprise multiple types of tissues and cells, microdosimetry is currently the subject of considerable development. Organ microdose and tumour dose must take into account the size of the irradiated tissues and the linear energy transfer path length to accurately estimate the true radiation-absorbed dose.

As a rule of thumb, tumour response will depend on the amount of tissue being irradiated as well as the radiation sensitivity of the tissue. Radiosensitive tumours such as lymphoma may have complete responses with radiation doses in the range of 1,500 $2,000 \mathrm{cGy}$, while solid tumours typically require 3,500-10,000 cGy for a meaningful response $^{122,123}$. Normal tissue radiosensitivity also varies from the bone marrow (typically $>150 \mathrm{cGy})$ to the lung and kidney $(1,500-2,000 \mathrm{cGy})$. Due to its quantitative nature, positron emission tomography (PET) imaging has been introduced as an optimal tool for theranostic imaging to determine radiation-absorbed doses to tumour and normal tissues $^{124}$.

\section{Features of the RIT approach}

The therapeutic principle of RIT is based on the selective targeting of tumours relative to normal tissues, creating a therapeutic index. Ideally, this index would be infinite, i.e., the radiation would be deposited only in the tumour. In practice, this ideal is never achieved since irradiation of normal radiosensitive tissues occurs during the process of targeting itself (i.e., the bystander effect). Delivery of RIT is simple from the patient's perspective and may be more convenient than conventional chemotherapy. RIT is administered over a matter of minutes, delivering the radiation payload over days during which the patient does not need to return for additional injections.

\section{Tumour antigen targets}

Selection of the optimal cell surface antigen and targeting antibody is critical to the success of a therapeutic program. An ideal antigen for RIT is expressed at a high, uniform density on the surface of all tumour cells, not expressed on normal cells, and not 'shed' into the bloodstream.

A detailed list of antigen targets for clinically useful antibodies has been summarized in a recent review ${ }^{2}$. Antigenic targets are usually tumour cell surface-expressed macromolecules, easily accessible from the blood and extracellular fluid, and include the hematopoietic cluster of differentiation ("CD") antigens that are expressed during hematopoietic maturation of distinct cell lineages. These antigenic targets also include cell surface glycoproteins (e.g., mucins), enzymes such as prostate-specific membrane antigen (PSMA) and carbonic anhydrase IX (CAIX), glycolipids such as GD2, carbohydrates such as Lewis ${ }^{\mathrm{y}}$, stromal components (e.g., fibroblast activation protein-a (FAPa, components of blood 
vessels (e.g., integrins, vascular endothelial growth factor receptor (VEGFR), or the amino domain of fibronectin B), and signal transduction molecules (e.g., growth factor receptors, epidermal growth factor receptor (EGFR), and HER2 (also known as ERBB2)).

Although no perfect antigen-antibody pair for RIT exists, several excellent targets have been identified for lymphoma, including CD20, CD22, and human leukocyte antigen-DR (HLADR) for B-cell non-Hodgkin's lymphoma (B-NHL); CD33 and CD45 for acute myeloid leukemia (AML) (Figure 1); and PSMA and the extra domain B (ED-B) of fibronectin for solid tumours ${ }^{3-11}$. In particular, CD20 is a successful target in B-cell malignancies. CD20 is a 35,000 Da non-glycosylated phosphoprotein that is expressed on the surface of nearly all mature B-lymphoid cells and $95 \%$ of B-cell lymphomas ${ }^{12,13}$.

The metabolism of the antibody-antigen complex is an important consideration in the choice of the optimal radionuclide for use in RIT. Metabolism of the radionuclide by the cell may either enhance the anti-cancer effects by retaining the radionuclide within lysosomes or storage proteins, or reduce the radiation effects by expelling the radioactivity from the cell. Some antigens, such as CD5 or PSMA, are rapidly internalized by the cancer cell with resulting catabolism, including disconnecting the radiolabel from the antibody. Nonresidualizing radiolabels such as radioactive iodides are rapidly released as a result of catabolism after internalization, whereas radiometal labels tend to be sequestered within the cell and retained (residualized). Other types of antigens such as GPA33 and CD20 are much more slowly turned over, and non-residualizing isotopes may be retained on the tumour cell membrane with relatively slow release.

Residualizing or radiometal labels are conducive to RIT because they are likely to be highly concentrated in neoplastic tissue, due to progressive antigen-antibody complex internalization. However, a residualizing label may also be retained in normal tissue, such as liver or kidney, leading to concerns of radiation damage. [Box 2]

\section{Box 2}

"Rule of thumb" considerations in selecting antibody-antigen targeting for radioimmunotherapy

1. Tumour specificity: antigen is abundantly expressed on tumour cells, and much less on normal tissues.

2. Antigen expression on tumour cells is high: $>100,000$ sites per cancer cell.

3. High-binding affinity to enhance selective neoplastic uptake; antibody binding affinity for cognate antigen is $\sim 10^{9}$ liters/mole.

4. Fate of antigen-antibody complex: once binding is assured, this should be known. If internalized, a residualizing radiolabel (such as a radiometal) should be used; if not internalized, a non-residualizing radiolabel such as radioiodine may be used.

5. Immunoreactivity of radiolabeled antibody should be as high as possible: ideally, $>90 \%$. 
6. The radionuclide for labeling is selected based on the cancer cell type being targeted. Beta particles have a long range of deposition in tissues-usually many cell diameters. This may be advantageous for killing adjacent tumour and stromal tissue in a tumour mass, for which there is heterogenous antigen expression. Alpha particles have a much shorter range and deposit high energy so that a few radioactive decays will kill a single cell. Alpha particles are advantageous for leukaemias, single cells, and a few cells in clusters.

7. In vivo biodistribution of radiolabeled antibody form should show low uptake in organs such as the liver, spleen, and kidney. Therapeutic Index between tumour and radiosensitive tissues, especially for solid tumours, should be $>10$ for kidney and $>50$ for bone marrow ${ }^{122,123}$.

\section{Radionuclide selection}

Radiation from RIT kills cells when their DNA is damaged beyond the capacity of the cancer cell to repair. Multiple therapeutic radionuclides tightly attached to antibodies by selective chemistries are available and may be chosen either alone or in combination to suit a specific treatment purpose. Radionuclides available for therapy emit particulate radiation (beta, alpha or auger emission) that deposits a considerable amount of their radiation energy within the tumour mass (Supplementary Table S1).

The choice of the optimal radionuclide for RIT depends on both intended use and practical considerations governing specific application. ${ }^{131} \mathrm{I}$ and ${ }^{90} \mathrm{Y}$, both $\beta$-particle-emitting isotopes, have been employed in $>95 \%$ of clinical RIT trials and represent the current standard to which all other radionuclides are compared ${ }^{14-17 . ~ 131 ~ I ~ a n d ~}{ }^{90} \mathrm{Y}$ qualify for RIT because of their favorable emission characteristics, availability and tractable radiochemistry, which permits reliable and stable attachment to antibodies. Furthermore, hundreds of published clinical trials attest to their efficacy for the treatment of haematological and solid malignancies. Both isotopes feature certain advantages: ${ }^{131} \mathrm{I}$ is relatively inexpensive, can be used for both imaging and therapy, and has a long successful history of treating several malignancies, including thyroid cancer, NHL and AML. However, ${ }^{131}$ I-labeled proteins degrade rapidly if endocytosed into tumour cells, resulting in the release of ${ }^{131} \mathrm{I}$-tyrosine and free ${ }^{131} \mathrm{I}$ into the bloodstream ${ }^{18-20}$. In addition, the $\gamma$-rays emitted by ${ }^{131}$ I may pose a radiation risk to family members and healthcare personnel and patient hospitalization for radiation isolation may be required if large doses are injected.

${ }^{90} \mathrm{Y}$ is a reasonable alternative $\beta$-emitter for therapeutic studies, and emits $\beta$-particles almost exclusively. Since this form of radiation does not leave the patient's body, there is less exposure to caregivers and family members. ${ }^{90} \mathrm{Y}$ emits $\beta$-particles that are five times more energetic than those of ${ }^{131} \mathrm{I}$, emits relatively weak electromagnetic radiation (Bremsstrahlung ), is easily administered to outpatients, and is stably retained by tumour cells even after endocytosis. For both ${ }^{131} \mathrm{I}$ and ${ }^{90} \mathrm{Y}$, dose-limiting myelosuppression at conventional doses ${ }^{21,22}$ and cardiopulmonary toxicities at myeloablative doses used in the setting of stem cell transplantation may be observed ${ }^{4,23}$. 
Alpha particle-emitting radionuclides exhibit very high potency, making them attractive alternatives, or adjuncts, to the $\beta$-emitting radionuclides in $\mathrm{RIT}^{24,25}$. This higher potency is due to the fact that emission of an a particle releases a large amount of energy in a linear fashion within a few cell diameters $(50-90 \mu \mathrm{m})$. The high linear energy transfer (LET) of aemitters $(\sim 100 \mathrm{keV} / \mu \mathrm{m})$ confers a high relative biological effectiveness (RBE) for cell killing ${ }^{26-28}$. High RBE derives from the fact that the extent of damage (e.g., DNA double strand breaks) to the cell from a particle exposure is so great that cell repair mechanisms are not effective and the cell undergoes apoptosis or necrosis. Furthermore, unlike $\beta$-emitting radionuclides, the effect of oxygen on cell killing is minimal, and thus effective cell killing can be expected even in areas of the tumour that are hypoxic ${ }^{26,28}$. Due to availability and decay properties, only a few a-emitting radionuclides are considered suitable for in vivo applications, including ${ }^{213} \mathrm{Bi}$ (biological half-life $\left.\left(\mathrm{t}_{1 / 2}\right)=45.6 \mathrm{~min}\right),{ }^{211} \mathrm{At}\left(\mathrm{t}_{1 / 2}=7.2\right.$ $\mathrm{h}),{ }^{225} \mathrm{Ac}\left(\mathrm{t}_{1 / 2}=10\right.$ days $){ }^{27-34},{ }^{223} \mathrm{Ra}\left(\mathrm{t}_{1 / 2}=11.4\right.$ days $)$; and ${ }^{212} \mathrm{~Pb}\left(\mathrm{t}_{1 / 2}=10.6 \mathrm{~h}\right)$.

\section{Molecular pharmacology of antibody-antigen targeting}

The molecular pharmacology of antigen targeting by antibody takes into account the timedependent biodistribution in physiological spaces after parenteral injection. The goal is to describe the immunokinetics of radioactive antibody targeting in a mathematical model, which comprehensively characterize the factors that determine the therapeutic index and radiation-absorbed dose for tumour tissue. A practical purpose for this modelling strategy is to identify approaches that will lead to optimized RIT under the proposed conditions of use.

Such a model has been developed for the relatively straightforward two compartment situations in which ${ }^{131} \mathrm{I}-3 \mathrm{~F} 8$ or ${ }^{131} \mathrm{I}-8 \mathrm{H} 9$ monoclonal antibodies are administered intrathecally for the treatment of recurrent neuroblastoma that is metastatic to the leptomeninges. These radioantibodies are injected into the intraventricular space in the brain, followed by subsequent distribution through the cerebral spinal fluid (CSF; approximately $150 \mathrm{ml}$ of volume). A simplified assumption for the model-which is reasonable for leptomeningeal metastasis - was that the distribution of the tumour was only one cell thick, such that the issue of diffusion of antibody through the tumour mass could be ignored ${ }^{35}$. A series of differential equations was used to provide a mathematical description of the compartments, including rates of exchange through both bulk flow and diffusion of antibody, half-life of isotope, specific activity of the antibody, percentage of the radioantibody that was immunoreactive, and antigen density on the tumour. Antigen-specific binding to tumour and non-specific binding to normal tissues was also considered.

The results showed a high correlation with the observed clearance and distribution within the CSF. The model made a number of useful predictions, which were subsequently implemented into clinical practice, including: increasing immunoreactivity from $10 \%$ to $80 \%$, which improved the therapeutic index 7.4 times; dividing the single therapy dose into four doses with a mass of about $1.4 \mathrm{mg}$ each, for a radioantibody with an affinity of $10^{-9}$ Liters/Moles (L/M); and immunoreactivity of 50\% was predicted to be sufficient to deliver more than 100Gy to the tumour with less than 10Gy to normal tissues. The radioantibody distribution is documented in Figure 2, which displays a quantitative PET image of ${ }^{124} \mathrm{I}-8 \mathrm{H} 9$, obtained at 2 hours, 24 hours, and 48 hours after intrathecal injection of 
radioantibody. Major responses and improvement in long-term survival after these CNS events have been achieved using this compartmental RIT (cRIT) approach ${ }^{36,37}$ (Supplemental Figure S1). The published survival curve for the first 21 patients with neuroblastoma treated with an intra-Ommaya cRIT-based regimen, compared to patients with CNS neuroblastoma treated with other conventional regimens without cRIT, is shown in Supplemental Figure S2. In a recent update presented at the Advances in Neuroblastoma Research (Cologne, 2014), survival data on 43 patients with CNS neuroblastoma treated with cRIT-based therapy demonstrated overall survival of $62 \%$, median 5.3 years (1.3-10.8 years $)^{38}$.

For intravenous administration of RIT, the situation is considerably more complex, and mathematical models intended to quantitatively describe the process of antibody-antigen targeting must take a number of additional factors into account, such as the large volume of distribution of antibody in vivo (in adults up to $15 \mathrm{~L}$ for the extracellular space, and must include specific uptake in the actively competing non-tumour tissues that may contain the antigen, as well as catabolism and clearance in the liver, kidney and gut. At the tumour site, there is evidence that the binding of antigen and antibody drives uptake after intravenous administration, just as occurs after intrathecal administration of cRIT. For example, in a recent study using intravenously administered ${ }^{124} \mathrm{I}-\mathrm{A} 33$ antibody for patients with colorectal cancer, the uptake was demonstrated to be linearly related to the expression of GPA33 antigen on the cell surface ${ }^{39,40}$. This finding is consistent with the chemical laws of mass action, and indicates that a complete model that accurately describes in vivo targeting must also include nonlinear or saturation kinetics (Supplemental Figure S3).

Wittrup et al. ${ }^{41}$ have developed a practical guide for selecting targeting agents for optimal uptake in the tumour mass itself after intravenous administration, using a kinetic model based on chemical engineering principles. The guide includes a set of design features for tumour targeting agents with respect to agent size, binding affinity, and target antigens. Examples are provided principally from mouse studies offering partial validation of the model predictions.

This theoretical analysis suggests that tumour targeting agents the size of whole IgG, $20 \mathrm{~nm}$ or so in diameter, strike the right balance between diffusion rates into the tumour mass and renal clearance to allow for optimal tumour uptake. By contrast, agents that are much smaller (i.e., 6-8 nm), such as Fv fragments, are excreted through the kidney too rapidly to diffuse into the center of the tumour mass. The model also takes into account pharmacological dose, binding affinity of the agent for its cognate antigen, and antigen expression level. This model predicts that for binding affinities of less than $10 \mathrm{~nm}$ or so, molecules the size of IgG are not greatly affected as affinity increases with regard to uptake, but that smaller molecules (less than $5 \mathrm{~nm}$ ) benefit greatly from the high affinity with increased uptake. Emphasis is also placed on a balance between mass delivered to the tumour and binding affinity. Weinstein et al. ${ }^{42}$ introduced the term "binding site barrier," proposing that uptake of very high affinity antibodies could be limited to the periphery of tumours, unless the appropriate pharmacologic dose was employed to allow saturation of outer binding sites, so that diffusion into the center of the mass could occur. An additional important contribution provided by Wittrup et al. is the important role that endocytosis of 
the antigen-antibody complex may have in limiting diffusion throughout the tumour mass. Thus, there is a balance among diffusion, antigen-antibody binding, and internalization with respect to in vivo targeting.

\section{RIT of haematological malignancies}

RIT is a particularly attractive approach for haematologic malignancies for a number of reasons, including: many lineage-specific cell surface antigens that are not expressed on other tissues have been identified; a multitude of high-quality antibodies that target haematological malignancies are available; leukaemias and lymphomas are exquisitely sensitive to radiation therapy; and human anti-mouse antibodies (HAMAs) are less likely to form in patients with haematological malignancies than in patients with solid tumours owing to the inherent immunosuppressive nature of haematopoietic malignancies (Figure 4). In addition, the widespread availability of haematopoietic cell transplantation makes myeloablative RIT an attractive option to increase the radiation dose delivered to malignant cells, while rescuing patients from unacceptable extramedullary toxicities $4,10,23,43-46$. This is particularly true when the patient's own stem cells can be harvested prior to receiving the high dose of RIT; this type of autologous transplant, also called stem cell rescue, has become routine in many oncology centers, and is also used in the context of high-dose chemotherapy.

The initial studies ${ }^{2}$ using high-dose RIT in myeloablative doses followed by bone marrow transplant set a high standard for the magnitude of response ( $>80 \%$ complete remissions) as well as duration of response (median $>5$ years), and a number of patients with advanced Bcell malignancies were permanently cured (Table 1). However, the technical challenge of bone marrow transplantation and high-dose ${ }^{131}$ I labeling discouraged widespread application. The development of outpatient RIT regimens using smaller doses of radiation, along with tailored doses based on individualized patient clearance and metabolism of a diagnostic level pre-dose, gave the entire effort a greater impetus, and yielded two US Food and Drug Administration (FDA)-approved drugs: one labeled with ${ }^{131} \mathrm{I}$ ( ${ }^{131} \mathrm{I}$-tositumomab) and another with ${ }^{90} \mathrm{Y}\left({ }^{90} \mathrm{Y}\right.$-ibritumomab tiuxetan). Both agents target $\mathrm{CD} 20$ as a part of regimens that treat B-cell lymphomas and show considerable activity in non-myeloablative regimens of modest toxicity.

The majority of RIT clinical trials for haematopoietic tumours have focused on radiolabeled CD20 antibodies (Table 1). CD20 antibodies conjugated to ${ }^{131} \mathrm{I}$ or ${ }^{90} \mathrm{Y}$ produce higher overall response rates (ORR) and complete response rates (60-80\% ORR and 15-40\% CRs) in relapsed NHL than unlabeled antibodies, such as rituximab ${ }^{3-5,23,47-49}$, as demonstrated in two randomized studies 22,50 . The median remission duration with non-myeloablative RIT has been one or two years in most studies, with $15-20 \%$ of patients achieving sustained remissions, and in some cases, even 10 years or more ${ }^{51}$.

RIT has been well tolerated, though myelosuppression, fatigue, thyroid dysfunction (with ${ }^{131} \mathrm{I}$ ), and HAMA formation have been observed. Myelosuppression and secondary malignancies have been reported, but their incidence is not increased when compared to patients treated with chemotherapy ${ }^{52}$. Because of higher risk of myelosuppression in 
patients with significant bone marrow involvement (>25\%) or limited bone marrow reserve, ${ }^{131}$ I tositumomab or ${ }^{90} \mathrm{Y}$ ibritumomab tiuxetan is not recommended. Nonetheless, some studies suggest that lower adjusted activities may be administered ${ }^{53}$. The incidence of delayed second malignancies or myelodysplasia associated with RIT has been reported for patients with haematological malignancy treated with ${ }^{131} \mathrm{I}$ tositumomab, at $3.5 \%{ }^{52}$, and for ${ }^{90} \mathrm{Y}$-ibritumomab tiuxetan at $2.5 \%{ }^{54}$.

Five strategies have been proposed to enhance the durability of responses: incorporation of RIT into front-line treatment for NHL; use of myeloablative doses of RIT with autologous haematopoietic stem cell transplant; multi-step 'pretargeting' protocols (discussed below); combining RIT with other monoclonal antibodies ${ }^{55}$; and simultaneous targeting of multiple B-cell antigens ${ }^{11}$. (See Table 1 for a summary of myeloablative approaches). With the advent of outpatient haematopoietic stem cell transplantation, RIT alone or in combination with other treatments is becoming increasingly practical.

In this regard, preclinical investigations suggest that the chemotherapy drugs fludarabine and cytosine arabinoside are synergistic with RIT, and that etoposide, doxorubicin, and camptothecins can produce supra-additive benefits when combined with radiolabeled antibodies ${ }^{56}$. Clinical trials assessing the efficacy of concurrent fludarabine and high-dose RIT $^{57}$ or etoposide, cyclophosphamide, and RIT ${ }^{58}$ have validated the promise of these combinations. An alternative approach is to combine RIT targeting one antigen with unlabeled monoclonal antibodies targeting a different antigen, as has been done with ${ }^{90} \mathrm{Y}$ epratuzumab tetraxetan (anti-CD22) combined with veltuzumab (anti-CD20). ${ }^{59}$

\section{Incorporation of RIT into front-line therapy of NHL}

Seven Phase II studies and two Phase III studies have tested RIT in patients newly diagnosed with NHL who received front-line therapy either alone or as consolidation following chemotherapy. ${ }^{3,60-67}$ These studies have all demonstrated efficacy with ORRs of 90-100\% and CRs of 60-100\% (Figure 3A). Also, the CRs induced by this approach have been very durable, with median remission durations exceeding six years in many studies 3,60 (Figure 3B). Upfront RIT converted many partial responses elicited with immunotherapy or chemotherapy to CRs, and thus, many PCR-positive patients that express specific tumour cell-associated DNA (PCR-positive) became PCR-negative patients ${ }^{60,61,64}$. The efficacy of this strategy has been validated in a Phase III randomized trial of ${ }^{90} \mathrm{Y}$-ibritumomab tiuxetan consolidation after first remission in advanced-stage follicular lymphomas ${ }^{68}$. These findings have led to the regulatory approval of ${ }^{90} \mathrm{Y}$-ibritumomab tiuxetan RIT as first-line consolidation therapy in both Europe and the US. A second Phase III study comparing frontline $\mathrm{CHOP}$ chemotherapy regimen with ${ }^{131} \mathrm{I}$-tositumomab consolidation with $\mathrm{CHOP}$ chemotherapy plus six doses of rituximab did not reach statistical significance ${ }^{69,70}$.

Despite the safety and efficacy of RIT for lymphomas and the approval of two radioimmunoconjugates by the FDA, this therapeutic modality is less frequently used than chemotherapy regimens and one of the approved agents, ${ }^{131} \mathrm{I}$-tositumomab (Bexxar ${ }^{\mathrm{TM}}$ ), is no longer marketed. The limited adoption of RIT by the medical community, despite its advantages, appears to result from a combination of factors, including concerns about inducing myelodysplasia, the availability of multiple novel competing targeted agents 
(ibrutinib, idelalisib, brentuximab vedotin), and the inability of practicing haematologists and oncologists to administer the agents in their offices ${ }^{71}$. It remains to be seen whether future innovations (pretargeting, alpha emitters, etc.) will enhance the efficacy of the approach sufficiently to overcome these practical limitations, particularly with the likely emergence of additional competing treatments, including antibody-drug conjugates, which have shown considerable promise in early clinical trials and present fewer logistical hurdles for practicing physicians.

\section{RIT for other haematological malignancies}

AML has also been effectively treated using RIT targeting CD33, CD45 or CD66 ${ }^{72}$ (Table 1). Of particular promise in this setting are the alpha emitters ${ }^{212} \mathrm{Bi}$ and ${ }^{225} \mathrm{Ac}$. Radioimmunoconjugates of ${ }^{225} \mathrm{Ac}$ act as atomic nano-generators, delivering cascades of a particles to cancer cells, resulting in a potency estimated to be 1,000 times greater than ${ }^{213} \mathrm{Bi}$-conjugates, and perhaps 5,000-10,000 times the potency of the beta emitters $^{27,73}$. Promising preclinical and clinical studies of RIT have also been conducted targeting CD66 for AML, CD5 for chronic lymphocytic leukemia, CD30 and ferritin for Hodgkin's lymphoma, CD25 for acute T cell leukemia and lymphoma, and CD45 for peripheral $\mathrm{T}$ cell lymphomas ${ }^{74-77}$. These radioimmunoconjugates are likely to grow in importance in the years to come.

\section{RIT of solid tumours}

A large number of clinical trials with RIT administered intravenously have been reported over more than three decades, with modest clinical results (Table 2 and Supplementary Tables S2, S3, and S4). The extensive experience with IgG-based RIT comprising a variety of radionuclides leads to the conclusion that the therapeutic index for the antibody-antigen systems tested thus far is insufficient. This is because target-to-background ratios for tumour-to-normal tissue are inadequate due to the tendency of the $\operatorname{IgG}$ molecule to distribute in blood and other organs, as well as normal tissues of liver and especially bone marrow. Dose-limiting toxicity is almost exclusively haematopoietic. Observed responses include largely stable disease or reduction in tumour biomarkers (Table 2). In a few cases, there is a suggestion of enhanced survival, but actual shrinkage of tumour and well-documented RECIST (Response Evaluation Criteria in Solid Tumors) responses ${ }^{70}$ are few and far between. An approach to increase radiosensitivity by combining ${ }^{90} \mathrm{Y}$ clivatuzumab tetraxetan (hPAM4), an antibody that recognizes pancreatic cancer, with low-dose gemcitabine has shown objective tumour responses by RECIST, with $16 \%$ partial remission ${ }^{78}$. These data have led to an ongoing phase III double-blind, randomized trial.

However, when the radioimmunoconjugate is injected directly into a body compartment in which the tumours are confined, tumour shrinkage and long-term impact on survival has been observed (discussed further below). Of course, these situations require special circumstances - the tumour must be accessible either for direct injection or within a compartment that can facilitate targeting. In preclinical studies, pretargeted RIT (PRIT; also called multistep targeting) enhances tumour uptake relative to normal tissues. The advantage of a multistep targeting approach is the high therapeutic ratio, even when administered 
intravenously. Finally, a combination of chemotherapy and RIT, along with the use of special radionuclides such as alpha emitters, is favorable in certain circumstances.

\section{Intra-compartmental therapy}

Intrathecal and intraventricular administration of ${ }^{131} \mathrm{I}-81 \mathrm{C} 6$ (a tenascin monoclonal antibody) for the treatment of leptomeningeal carcinomatosis and intra-tumoural therapy of malignant brain tumours have produced objective responses and prolonged patient survival ${ }^{79,}{ }^{80 .}{ }^{131}$ I-81C6 is an example of a-particle therapy for RIT of malignant glioma and, if problems of radionuclide supply can be overcome, it is likely to be used more extensively ${ }^{81}$.

Intraventricular ${ }^{131} \mathrm{I}-3 \mathrm{~F} 8$ (anti-GD2, NCT00445965) ${ }^{36}$ and ${ }^{131} \mathrm{I}-8 \mathrm{H} 9$ (anti-B7-H3, NCT00089245) ${ }^{37,82}$ are also being tested in leptomeningeal cancers in both children and adults, with highly favorable CSF-to-blood radiation dose ratios. Children with recurrent neuroblastoma with CNS metastases have achieved long-term remissions ${ }^{37}$. The apparent reason the intra-compartmental injections are more effective than systemic injections is that there is more effective targeting to tumour with typical radiation-absorbed doses in the $5,000-10,000$ cGy range, which is approximately 10 times the dose typically achieved with intravenous injection. In all probability, this is due to simple binding kinetics, since after direct intrathecal injection, the total RIT is distributed in no more than $150 \mathrm{~mL}$ of CSF within the intrathecal compartment.

Furthermore, the CSF is devoid of white cells or proteins that can interfere with antibody binding in comparison to much larger dilution when the dose is distributed systemically within five liters of blood volume. In addition, CSF flows in one direction and renews every seven-eight hours, providing a built-in washout step for unbound RIT. The apparent absence of anatomic barrier could also facilitate the movement of antibodies between CSF and the extracellular space of the brain ${ }^{83,84}$, especially if there is damage to the meninges either by tumour or surgery. Since there is no B7-H3 expression in normal brain tissue, ${ }^{124} \mathrm{I}-8 \mathrm{H} 9$ (a $\beta$ emitter that targets B7-H3) is being tested successfully as a theranostic agent by conventionenhanced delivery into brainstem gliomas (NCT01502917).

\section{Tumour targeting with intravenous injection of RIT}

The slow clearance of unbound RIT from the blood circulation and the resulting high levels of background radioactivity are pharmacokinetic features that limit the tumour-to-normal organ ratios of absorbed radiation that can be achieved ${ }^{85-87}$. One approach to reduce the toxicity of RIT is to employ smaller antibody moieties to decrease the circulating half-life of the RIT ${ }^{88-91}$. Although opinions vary on the clinical potential of antibody fragments for RIT, most experts have concluded that the smaller molecules penetrate solid tumours faster, more deeply, and more homogeneously than intact antibodies, but achieve lower intratumoural concentrations, exhibit shorter tumour retention times than intact antibodies, and may demonstrate undesirable renal accumulation ${ }^{92}$. Approaches to increase therapeutic efficacy have included dose fractionation with the expectation of bone marrow recovery in between doses, leading to higher administered doses. This dose fractionation approach has shown to be feasible in lymphoma ${ }^{6,93}$ and in solid tumours ${ }^{78}$. 
In particular, to enhance the therapeutic index in solid tumours relative to normal tissues, three avenues are being followed that appear to show some promise, particularly in preclinical studies: PRIT, the addition of chemotherapy to RIT, and the application of radionuclides with favorable emissions, especially alpha emitters.

\section{PRIT}

PRIT employs multi-step pretargeting to dissociate the slow distribution phase of the antibody molecule from the administration of the therapeutic radionuclide. These strategies administer tumour-reactive antibody in a non-radioactive form, allowing it to localize to solid tumour sites and accumulate without subjecting the rest of the body to non-specific irradiation from circulating RIT $^{85}$, 90, 94-99. After maximal accumulation of antibody in the tumour, a small molecular weight, radioactive moiety with high affinity for the tumourreactive antibody is administered. Because of its small size, this second reagent penetrates solid tumours rapidly where the pretargeted antibody traps it. Furthermore, unbound molecules of the second (radioactive) reagent are small enough to be rapidly cleared from the blood and excreted in the urine. In some pre-targeting approaches, a clearing agent can be injected shortly before the radiolabeled small molecule to remove the unbound antibody from the bloodstream and prevent it from complexing with the radiolabeled small molecule in circulation $95,96,100,101$. Several strategies have been proposed and implemented preclinically to accomplish this binding, but one of the most promising exploits the extraordinarily high affinity of avidin (or streptavidin) for biotin (Figure 4).

\section{Bispecific antibodies}

Goldenberg et al..$^{90}$ have developed bivalent haptens [G] that permit cooperative binding, thereby linking two bispecific antibodies together on the tumour cell surface using the bivalent hapten (e.g., histamine-succinyl-glycine (HSG)) as a bridge. Their 'affinity enhancement system' employs fragment antigen-binding (Fab) fragments of tumour antibodies with Fab fragments of hapten antibodies (Figure 4). Spontaneous cyclization of the bivalent hapten with two molecules of bispecific Fab binding to two antigen molecules on the tumour cell surface stabilizes the radiolabeled ligand on the cell surface through cooperative binding. HSG-hapten-containing peptides have been synthesized with chelates for either radiometals $\left({ }^{111} \mathrm{In},{ }^{90} \mathrm{Y}\right.$, or $\left.{ }^{177} \mathrm{Lu}\right)$ or a technetium-rhenium chelate. They can be radiolabeled to a highly specific activity that avoids the need for purification ${ }^{102}$. In preclinical studies, this approach has yielded impressive results in both imaging and therapeutic applications ${ }^{103,104}$.

A clever modification of the bispecific antibody targeting approach utilizes molecularly engineered 'dimerization and docking domains' containing self-assembling protein kinase A motifs with engineered cysteine residues ${ }^{105,} 106$ (Figure 4). Another novel approach to bispecific antibody pretargeting has been suggested by Goodwin and Meares ${ }^{98}$, who have developed molecularly engineered bispecific antibodies incorporating complementary reactive groups in the antibody binding pocket, which bind covalently and irreversibly to radiolabeled electrophilic ligands ${ }^{107,108}$. Potential advantages of this approach compared with the streptavidin-biotin approach are less immunogenicity and faster and more homogeneous penetration into tumour sites, due to the smaller size of a radiometal DOTA. 
Multi-step targeting has been limited so far by immunogenicity with certain high-affinity reagent combinations (e.g., immune responses to streptavidins or unusual antibody forms), the absence of a clinical clearing agent, difficulty in manufacture and purification, and interfering substances in human blood.

A novel solution to many of these problems has been proposed using a modular (IgG-scFv) antibody developed by Wittrup et al. ${ }^{109}$ with an IgG portion specific for tumour and the high-affinity scFv specific for DOTA-metal. The bispecific bivalent constructs have high avidity for both the tumour and radiolabeled DOTA, while the large molecular weight ( 200 $\mathrm{kD}$ ) ensures a long plasma half-life for optimal tumour targeting. More importantly, since the scFv affinity for DOTA depends on the chelated metal, ranging from $8 \mathrm{pM}-50 \mathrm{nM}$ affinity, dextrans or dendrimer carrying DOTA-metal of low affinity for $\mathrm{scFv}$ can be exploited as clearing agents. Besides targeting ${ }^{90} \mathrm{Y}(15 \mathrm{pM}$ affinity for $\mathrm{scFv})$ or ${ }^{177} \mathrm{Lu}(11$ pM affinity for scFv) in RIT, DOTA-metal provides a convenient method to target nanoparticles. Another novel pretargeting approach utilizes complementary hybridization (Watson-Crick pairing) of DNA and other oligomers, particularly phosphorodiamidate morpholino oligomers (MORFs), as a recognition system ${ }^{110,111}$ (Figure 4).

Regardless of the PRIT approach used, all investigators who have conducted comparative tumour targeting studies in animals have concluded that pretargeting is superior to conventional one-step RIT to improve tumour-to-normal organ ratios of absorbed radioactivity and tumour responses in preclinical models. For example, in a DOTA-PRIT approach using bifunctional antibody with antigen reactivity to GD2 ganglioside in neuroblastoma xenografts, therapeutic index (TI) for tumour to bone marrow was 50:1, while TI for kidney was 7 , and CRs were observed with no detectable toxicity ${ }^{112}$.

\section{Pilot PRIT human studies}

Pilot clinical trials of PRIT have also been very encouraging in patients with both solid tumours and lymphoma ${ }^{113-115}$. In one pilot study investigating streptavidin-biotin PRIT for NHL, four of seven patients with advanced NHL (who had failed multiple prior therapies including haematopoietic stem cell transplantation and prior conventional RIT) achieved objective responses, including two CRs ${ }^{115}$. Additional studies using streptavidin-biotin pretargeting are underway for patients with AML, acute lymphoblastic leukemia (ALL), and myelodysplastic syndrome (MDS) (Pagel \& Press et al., unpublished data). Pretargeting using antibodies to carcinoembryonic antigen (CEA) ${ }^{116}$ was tested in colorectal cancer $(\mathrm{CRC})^{117}$, small-cell lung cancer (SCLC) ${ }^{118}$, and medullary thyroid carcinoma ${ }^{116,119}$; NRLU-10 in $\mathrm{CRC}^{115}$; CC49 in gastrointestinal cancer ${ }^{114}$; and CD20 monoclonal antibodies in $\mathrm{NHL}^{113}, 115$ —all with variable success. A three-step approach using biotinylated monoclonal antibodies, followed by avidin-streptavidin and then biotinylated radiometalchelate, was also applied to patients with glioma with encouraging results ${ }^{120,121 .}$

The goal of these approaches is to improve therapeutic index, and localization can be impressive in antigen-expressing tissues. A case in point is the study of NR-LU-10 in CRC, which has showed documented responses in patient tumours. However, studies in humans were suspended when gut toxicity developed. In retrospect, targeting of antigen expressed in 
normal gut was the likely cause for serious toxicity. PRIT studies in humans must be cautiously performed, with attention to possible targeting to normal tissues, by concomitant imaging and normal tissue dosimetry estimates that are carried out in parallel with therapeutic regimen (theranostic approach). [Box 3]

\section{Box 3}

\section{Development of human immune targeting reagents}

The molecular engineering of antibodies has resulted in the development of a wide range of potential antibody forms that can be radiolabeled and serve as a key component of the radioimmunotherapy (RIT) approach. An ideal antibody binds with high avidity to the target antigen, exhibits minimal binding to non-malignant tissues, penetrates rapidly and uniformly into tumour nodules, and clears from the blood circulation soon after maximal tumour binding is achieved to avoid non-specific irradiation of normal tissues by circulating RITs.

GD2 example: Antibody 3F8 and its humanized form, hu3F8, bind to the cell surface tumour target disialoganglioside (GD2; $\mathrm{Kd} \sim 10 \mathrm{nM}$ ), a ceramide-anchored antigen highly restricted in its tissue distribution, while shielded from the GD2(+) central nervous system (CNS) due to the blood-brain barrier ${ }^{125}$. GD2 is widely expressed among human tumours including neuroblastoma, bone sarcomas, soft-tissue sarcomas, small-cell lung cancer, retinoblastoma, brain tumours, and tumour stem cells ${ }^{126}$. In neuroblastoma, this antigen is abundant $\left(>10^{6} \%\right.$ cell), relatively homogeneous within and between tumours, and rarely lost following GD2-based immunotherapy ${ }^{126}$. Anti-GD2 antibodies for the treatment of metastatic neuroblastoma have proven safe even in young patients, with no late toxicities of CNS or peripheral nervous system with up to 20 years of follow-up ${ }^{127}$. Although 3F8 targets tumours in patients unusually well by immunoscintigraphy, the area under the curve (AUC) of tumour-to-blood ratio for intact IgG was never more than 5:1 even in preclinical models. With pretargeting strategies using biotin-streptavidin systems, the AUC ratios had substantially improved ${ }^{128}$. However, immunogenicity of streptavidin and the ubiquitous presence of biotin in tissue fluids will constrain clinical development until the advent of humanized pretargeted RIT (PRIT) strategies using the benzyl(Bn)DOTA - C825 system. C825 is an affinity-matured antibody that is specific for Bn-DOTA metal complex with differential affinities for radiometal-Bn-DOTA complexes. Utilizing hu3F8-C825 to deliver $\beta$ emitters such as ${ }^{177} \mathrm{Lu}$, radioactivity AUC ratios of >100:1 for blood and >10:1 for kidney are achieved, translating into complete tumour ablation with no dose-limiting toxicities in preclinical models ${ }^{112}$. The utility of this PRIT strategy has since been successfully applied to other human tumour targets.

\section{Conclusions}

In principle, intravenous RIT could deliver curative radiation to widely disseminated tumours within the human body. In practice, the effectiveness of RIT depends on the complex interplay of the tumour radiosensitivity and the amount of radiation that can be safely administered and targeted to the tumour. RIT delivered systemically has been most 
effective in haematopoietic cancers, even resulting in long-term response and 'cures,' especially when targeting CD20, where both ${ }^{131} \mathrm{I}$ and ${ }^{90} \mathrm{Y}$ radiation have prolonged patient survival for tumours that are refractory to chemotherapy or unlabeled antibody.

Alpha-emitter therapy with ${ }^{225} \mathrm{Ac}$ has been effective when carried by IgG antibodies targeting CD33 or CD45 on human leukaemia cells. In solid tumours, long-term remissions have been achieved using compartmental RIT injections especially via the intrathecal route, probably because of the better access of the antibody to tumour-associated antigens in these tissues. Intravenous RIT has been largely ineffective in solid tumours. Novel methods to improve therapeutic index have greatly enhanced the prospects of the intravenous route to deliver sufficient radiation to kill more radioresistant solid tumours. One promising strategy is multi-step targeting, which pretargets the tumour with a bispecific antibody without its therapeutic payload, followed in sequence by the therapeutic ligand after the pre-targeted tumour antibody, which maximizes radiation in tumours compared to radiosensitive normal tissues. Through quantitative imaging methods such as PET, estimates of tumour dosimetry will become more precise in RIT, even at tumour sites deep within the body.

The major hurdle that needs to be overcome to achieve the full potential of RIT is delivering tumouricidal doses specifically to tumours, ranging from 3,000-5,000 cGy for more radiosensitive tumours such as haematopoietic tumours, and up to $10,000 \mathrm{cGy}$ for most radiation-resistant solid tumours, such as thyroid. This must be accomplished while sparing normal radiosensitive tissues so that organs such as the kidney, lung, colonic mucosa, and bone marrow receive less than 2,000, 1,500, 250, and $100 \mathrm{cGy}$, respectively. These dose estimates come from a variety of sources, including the external beam normal dose tolerance projections by Emami et al. ${ }^{122}$ estimates from Maxon ${ }^{123}$, as well as thresholds for kidneysparing dosing during peptide-targeted radiotherapy, which has emerged from recent large, yet unpublished, experiences (personal communication, Richard Baum, $\mathrm{MD}, \mathrm{PhD}$ ). In vivo targeting approaches come close to this optimal radiation balance already in some clinical scenarios, such as intrathecal injections for tumours invading the meninges, and intravenous injections in lymphomas, especially in conjunction with bone marrow sparing agents such as granulocyte colony-stimulating factor (GCSF) and stem cell rescue.

To aid the further refinement and optimization of RIT that is needed for clinical use, more effort should be placed in developing better real-time dosimetry methods, especially those that use the intrinsic theranostic features of the therapeutic radionuclides themselves. From a laboratory perspective, methods with increasingly better therapeutic ratios for PRIT are being developed, which should be encouraged. More effort in understanding the radiobiology of targeted therapy is sorely needed, especially with respect to whether the emission properties of therapeutic radionuclides can be optimally used in specific clinical situations to improve selective tumour killing. For example, alpha emitters and low-energy beta and conversion electron emitters may have intrinsic advantages because radiation is delivered primarily at the site of molecular targeting, rather than to innocent bystander cells. Also, a combination of radionuclides and antibody-antigen systems may overcome intrinsic heterogeneity and promote more effective targeting. 
Finally, this Review has not placed more emphasis on the most common solid tumours such as lung, colon, breast, and pancreas. This is because limited clinical benefit for these patients has been observed with RIT, despite considerable effort. Intravenously injected radiolabeled anti-tumour antibody to target solid tumours has not been effective for solid tumour therapy. In Supplementary Table S3, we provide a brief overview of solid tumour RIT reports to support this conclusion. Instead, our deliberate emphasis in this Review has been on the more successful application of RIT for haematological tumours, and intracompartmental solid tumour RIT has resulted in high response rates, often durable, and in some cases, longterm complete responses and cures. We focused on this to highlight what has worked for RIT as a basis for improving RIT for broader applications across the oncology spectrum. We come away with the belief that the greatest single limitation encountered so far is low therapeutic index for parenteral targeting in the setting of radioresistant solid tumours.

We are optimistic that a combination of advances, such as better dosimetry through quantitative imaging, radionuclides of higher potency, PRIT, as well as protein engineering of optimal antibody forms, will correct these problems and lead to future success in solid tumour RIT. In short, the field of RIT is still a challenging frontier, with many promising scientific opportunities waiting to be explored, particularly in the major solid tumours, where curative therapies are sorely needed.

\section{Supplementary Material}

Refer to Web version on PubMed Central for supplementary material.

\section{Acknowledgments}

This study was supported in part by the Center for Targeted Radioimmunotherapy and Theranostics, and the Ludwig Center for Cancer Immunotherapy. Additional financial support was provided by the Donna and Benjamin M. Rosen Chair and the Enid A. Haupt Chair (for S.M. Larson and N.K. Cheung, respectively). O. W. Press was supported in part by NCI PO1 CA044991, NCI R01 CA076287, NIH R01 CA109663, NCI R01 CA136639, NCI R01 CA154897, and NCI R01 CA138720. S. M. Larson was also supported in part by NCI P50-CA86438 and Sloan Kettering Institute. The authors wish to thank D.A. Scheinberg, J.D. Wolchok, and W.A. Weber for their valuable contributions to this research.

\section{GLOSSARY}

\section{Alpha particle}

AUC (area under the curve)

Beta particle

Bispecific antibodies
The size of a helium nucleus made up of two protons and two neutrons.

The overall amount of drug in the bloodstream after a dose.

An electron-like negative particle emitted from the nucleus of a beta-emitting radionuclide (e.g. I-131, Y-90).

An artificial protein composed of fragments of two different monoclonal antibodies, which consequently binds to two different types of antigen. 


\author{
Bremsstrahlung \\ Bystander effect \\ Cardiopulmonary \\ toxicity \\ Convention-enhanced \\ delivery \\ Dosimetry \\ DOTA
}

Fragment antigen-

binding (Fab)

fragments

Half-life

Hapten

Human anti-mouse antibody (HAMA)

Leptomeninges

Linear energy transfer

Myelosuppression

Ommaya reservoir
A type of electromagnetic radiation produced when a highenergy charged particle is decelerated or deflected by another charged particle.

The phenomenon in which radiation affects 'innocent' neighboring cells in addition to cells at the site of targeting.

The adverse effects on the blood systems, heart, or lungs resulting from exposure to toxic chemicals, e.g., cardiac ischemia, pulmonary inflammation, and an increased level of toxins in the blood.

A therapy in which therapeutic compounds are forced directly into the region of interest through a needle or cannula by applying a low-pressure gradient.

Assessment (by measurement or calculation) of radiation dose.

1,4,7,10-tetraazacyclododecane-1,4,7,10-tetraacetic acid.

DOTA functions as a chelating agent for the radioisotope ${ }^{90} \mathrm{Y}^{3+}$ or other radiometals. It can be conjugated to monoclonal antibodies by attachment of one of the four carboxyl groups as an amide.

A region on an antibody that binds to antigens and is composed of one constant and one variable domain of each of the heavy and the light chains.

The characteristic period of decay during which half of the population of radioactive atoms will undergo spontaneous radioactive decay.

A small molecule that, when combined with a larger carrier such as a protein, can elicit the production of antibodies that bind specifically to it (in the free or combined state).

An antibody found in humans that reacts to immunoglobins found in mice.

The two innermost layers of tissue (arachnoid mater and pia mater) that cover the brain and spinal cord.

The action of radiation upon matter that describes how much energy an ionizing particle transfers to the material transversed per unit distance.

A condition in which bone marrow activity is decreased, resulting in fewer red blood cells, white blood cells, and platelets.

A device surgically placed under the scalp and used to deliver anticancer drugs to the cerebrospinal fluid. 
Path length

\section{Phosphorodiamidate morpholino oligomers (MORFs)}

Residualized

\section{Single-chain variable fragment (scFv)}

Theranostics

Therapeutic index
The actual distance that a nuclear particle travels in tissue as part of the process of radioactive decay.

A family of synthetic oligomers that are water soluble and reported to be stable both in vitro and in vivo.

A radioactive form that is trapped in the tumour cell after catabolism of an internalized antigen-antibody complex (e.g., the radiometals ${ }^{177} \mathrm{Lu}$ or ${ }^{89} \mathrm{Zr}$ ); some non-residualizing radionuclides, such as radioiodine, can be made residualizing through the use of specific chemical constructs that limit catabolism in a way that traps radioiodine inside a tumour cell following delivery by a labeled monoclonal antibody.

A fusion protein of the variable regions of the heavy $(\mathrm{VH})$ and light (VL) chains of immunoglobulins, connected with a short linker peptide of $\sim 10-25$ amino acids.

Referring to a chemical moiety that can be used for both therapy and diagnostic purposes; e.g., the radioisotopes of Iodine, ${ }^{131} \mathrm{I}$ and ${ }^{124} \mathrm{I}$, can be used for both quantitative nuclear imaging and therapy.

The ratio between the dosage of a drug that causes a lethal effect and the dosage that causes a therapeutic effect; in the context of radioimmunotherapy, this is the ratio of radiationabsorbed dose to tumour divided by the dose to a radiosensitive tissue such as kidney or bone marrow.

\section{References}

1. Malaise EP, Fertil B, Chavaudra N, Guichard M. Distribution of radiation sensitivities for human tumor cells of specific histological types: comparison of in vitro to in vivo data. Int J Radiat Oncol Biol Phys. 1986; 12:617-24. [PubMed: 3009370]

2. Scott AM, Wolchok JD, Old LJ. Antibody therapy of cancer. Nat Rev Cancer. 2012; 12:278-87. Valuable review of general concepts of antigen targets on human tumours and the non-radioactive use of antibodies as therapeutics. [PubMed: 22437872]

3. Kaminski MS, et al. ${ }^{131}$ I-tositumomab therapy as initial treatment for follicular lymphoma. N Engl J Med. 2005; 352:441-9. Benefits of up-front treatment by RIT in lymphoma. [PubMed: 15689582]

4. Press OW, et al. Radiolabeled-antibody therapy of B-cell lymphoma with autologous bone marrow support. N Engl J Med. 1993; 329:1219-24. First demonstration of ability to achieve long-term remission with radioantibodies through RIT in advanced lymphoma. [PubMed: 7692295]

5. Witzig TE, et al. Treatment with ibritumomab tiuxetan radioimmunotherapy in patients with rituximab-refractory follicular non-Hodgkin's lymphoma. J Clin Oncol. 2002; 20:3262-9. [PubMed: 12149300]

6. DeNardo GL, et al. Maximum-tolerated dose, toxicity, and efficacy of ${ }^{131}$ I-Lym-1 antibody for fractionated radioimmunotherapy of non-Hodgkin's lymphoma. J Clin Oncol. 1998; 16:3246-56. [PubMed: 9779698] 
7. Sharkey RM, et al. Pretargeted versus directly targeted radioimmunotherapy combined with antiCD20 antibody consolidation therapy of non-Hodgkin lymphoma. J Nucl Med. 2009; 50:444-53. [PubMed: 19223402]

8. Morschhauser F, et al. High rates of durable responses with anti-CD22 fractionated radioimmunotherapy: results of a multicenter, phase I/II study in non-Hodgkin's lymphoma. J Clin Oncol. 2010; 28:3709-16. [PubMed: 20625137]

9. Rosenblat TL, et al. Sequential cytarabine and alpha-particle immunotherapy with bismuth-213lintuzumab (HuM195) for acute myeloid leukemia. Clin Cancer Res. 2010; 16:5303-11. [PubMed: 20858843]

10. Pagel JM, et al. Allogeneic hematopoietic cell transplantation after conditioning with 131I-antiCD45 antibody plus fludarabine and low-dose total body irradiation for elderly patients with advanced acute myeloid leukemia or high-risk myelodysplastic syndrome. Blood. 2009; 114:5444-53. Benefits of preconditioning with RIT in elderly patients undergoing bone marrow transplantation for advanced acute myleoid leukaemia and high-risk myelodysplastic syndrome. [PubMed: 19786617]

11. Pagel JM, et al. A comparative analysis of conventional and pretargeted radioimmunotherapy of Bcell lymphomas by targeting CD20, CD22, and HLA-DR singly and in combinations. Blood. 2009; 113:4903-13. [PubMed: 19124831]

12. Tedder TF, Engel P. CD20: a regulator of cell-cycle progression of B lymphocytes. Immunol Today. 1994; 15:450-4. [PubMed: 7524522]

13. Chang KL, Arber DA, Weiss LM. CD20: a Review. Applied Immunohistochem. 1996; 4:1-15.

14. Press OW. Radioimmunotherapy for non-Hodgkin's lymphomas: a historical perspective. Semin Oncol. 2003; 30:10-21. [PubMed: 12728403]

15. Press OW, Rasey J. Principles of radioimmunotherapy for hematologists and oncologists. Semin Oncol. 2000; 27:62-73. A general review of the principles of RIT. [PubMed: 11226002]

16. Press OW. Physics for practitioners: the use of radiolabeled monoclonal antibodies in B-cell nonHodgkin's lymphoma. Seminars in Hematology. 2000; 37(Suppl 7):2-8. [PubMed: 11147486]

17. Naruki Y, et al. Differential cellular catabolism of 111In, 90Y and 125I radiolabeled T101 antiCD5 monoclonal antibody. Int J Rad Appl Instrum B. 1990; 17:201-7. Initial comparison of the differential metabolism of radiometals and radioiodine as radiolabels for RIT. [PubMed: 1692819]

18. Geissler F, Anderson SK, Press O. Intracellular catabolism of radiolabeled anti-CD3 antibodies by leukemic T cells. Blood. 1991; 78:1864-74. [PubMed: 1832994]

19. Geissler F, Anderson SK, Venkatesan P, Press O. Intracellular catabolism of radiolabeled anti-mu antibodies by malignant B-cells. Cancer Res. 1992; 52:2907-15. [PubMed: 1581908]

20. Press OW, et al. Comparative metabolism and retention of iodine-125, yttrium-90, and indium-111 radioimmunoconjugates by cancer cells. Cancer Res. 1996; 56:2123-9. [PubMed: 8616860]

21. Kaminski MS, et al. Pivotal study of iodine I-131 tositumomab for chemotherapy-refractory lowgrade or transformed low-grade B-cell non-Hodgkin's lymphomas. J Clin Oncol. 2001; 19:391828. [PubMed: 11579112]

22. Witzig TE, et al. Randomized controlled trial of yttrium-90-labeled ibritumomab tiuxetan radioimmunotherapy versus rituximab immunotherapy for patients with relapsed or refractory lowgrade, follicular, or transformed B-cell non-Hodgkin's lymphoma. J Clin Oncol. 2002; 20:245363. [PubMed: 12011122]

23. Press OW, et al. Phase II trial of 131I-B1 (anti-CD20) antibody therapy with autologous stem cell transplantation for relapsed B cell lymphomas. Lancet. 1995; 346:336-40. [PubMed: 7623531]

24. Zalutsky MR. Targeted alpha-particle therapy of microscopic disease: providing a further rationale for clinical investigation. J Nucl Med. 2006; 47:1238-40. Rationale for alpha therapy illustrated with ${ }^{211}$ At. [PubMed: 16882999]

25. Jurcic JG, et al. Targeted alpha particle immunotherapy for myeloid leukemia. Blood. 2002; 100:1233-9. Early work with ${ }^{225}$ Ac. [PubMed: 12149203]

26. Hall, EJ.; Giaccia, AJ. Radiobiology for the radiologist. Lippincott Williams \& Wilkins; Philadelphia: 2005.

27. Mulford DA, Scheinberg DA, Jurcic JG. The promise of targeted alpha-particle therapy. J Nucl Med. 2005; 46(Suppl 1):199S-204S. [PubMed: 15653670] 
28. Zalutsky MR, Pozzi OR. Radioimmunotherapy with alpha-particle emitting radionuclides. Q J Nucl Med Mol Imaging. 2004; 48:289-96. [PubMed: 15640792]

29. Couturier O, et al. Cancer radioimmunotherapy with alpha-emitting nuclides. Eur J Nucl Med Mol Imaging. 2005; 32:601-14. [PubMed: 15841373]

30. McDevitt MR, et al. Tumor therapy with targeted atomic nanogenerators. Science. 2001; 294:1537-40. The concept of the alpha emitter ${ }^{225}$ Ac as an in vivo nanogenerator. [PubMed: $11711678]$

31. Nilsson S, et al. First clinical experience with alpha-emitting radium-223 in the treatment of skeletal metastases. Clin Cancer Res. 2005; 11:4451-9. [PubMed: 15958630]

32. Miederer M, et al. Pharmacokinetics, dosimetry, and toxicity of the targetable atomic generator, 225Ac-HuM195, in nonhuman primates. J Nucl Med. 2004; 45:129-37. [PubMed: 14734685]

33. Dahle J, et al. Targeted cancer therapy with a novel low-dose rate alpha-emitting radioimmunoconjugate. Blood. 2007; 110:2049-56. [PubMed: 17536011]

34. Waldmann T. ABCs of radioisotopes used for radioimmunotherapy: alpha- and beta-emitters. Leuk Lymphoma. 2003; 44(Suppl 3):S107-13. [PubMed: 15202533]

35. He P, et al. Two-compartment model of radioimmunotherapy delivered through cerebrospinal fluid. Eur J Nucl Med Mol Imaging. 2011; 38:334-42. [PubMed: 20936407]

36. Kramer K, et al. Phase I study of targeted radioimmunotherapy for leptomeningeal cancers using intra-Ommaya 131-I-3F8. J Clin Oncol. 2007; 25:5465-70. Induction of long-term responses in recurrent neuroblastoma with RIT. [PubMed: 18048828]

37. Kramer K, et al. Compartmental intrathecal radioimmunotherapy: results for treatment for metastatic CNS neuroblastoma. J Neurooncol. 2010; 97:409-18. Documentaion of an active intrathecal RIT regimen in patients with relapsed CNS neuroblastoma. [PubMed: 19890606]

38. Kramer, KB.; Modak, S.; Basu, EM.; Roberts, SS.; Pandit-Taskar, N.; Souweidane, MM.; Wolden, SL.; Cheung, NK. Advances in Neuroblastoma Research (ANR) Congress; Cologne, Germany. 2014.

39. Carrasquillo JA, et al. (124)I-huA33 antibody PET of colorectal cancer. J Nucl Med. 2011; 52:1173-80. Presurgical PET study of antibody targeting of CRC liver metastases as an optimal clinical research design for study of radioantibody targeting in vivo. [PubMed: 21764796]

40. O'Donoghue JA, et al. 124I-huA33 antibody uptake is driven by A33 antigen concentration in tissues from colorectal cancer patients imaged by immuno-PET. J Nucl Med. 2011; 52:1878-85. Law of mass action drives antibody-antibody binding at the tumour site. [PubMed: 22068895]

41. Wittrup KD, Thurber GM, Schmidt MM, Rhoden JJ. Practical theoretic guidance for the design of tumor-targeting agents. Methods Enzymol. 2012; 503:255-68. Role of diffusion into tumour, internalization of antigen, and renal clearance in tumour targeting. [PubMed: 22230572]

42. Fujimori K, Covell DG, Fletcher JE, Weinstein JN. A modeling analysis of monoclonal antibody percolation through tumors: a binding-site barrier. J Nucl Med. 1990; 31:1191-8. Initial description of binding site barrier in RIT. [PubMed: 2362198]

43. Pagel JM, et al. ${ }^{131}$ I-anti-CD45 antibody plus busulfan and cyclophosphamide before allogeneic hematopoietic cell transplantation for treatment of acute myeloid leukemia in first remission. Blood. 2006; 107:2184-91. [PubMed: 16254140]

44. Winter JN, et al. Yttrium-90 ibritumomab tiuxetan doses calculated to deliver up to 15 Gy to critical organs may be safely combined with high-dose BEAM and autologous transplantation in relapsed or refractory B-cell non-Hodgkin's lymphoma. J Clin Oncol. 2009; 27:1653-9. [PubMed: 19255322]

45. Devizzi L, et al. High-dose yttrium-90-ibritumomab tiuxetan with tandem stem-cell reinfusion: an outpatient preparative regimen for autologous hematopoietic cell transplantation. J Clin Oncol. 2008; 26:5175-82. [PubMed: 18854569]

46. Nademanee A, et al. A phase 1/2 trial of high-dose yttrium-90-ibritumomab tiuxetan in combination with high-dose etoposide and cyclophosphamide followed by autologous stem cell transplantation in patients with poor-risk or relapsed non-Hodgkin lymphoma. Blood. 2005; 106:2896-2902. [PubMed: 16002426] 
47. Kaminski MS, et al. Radioimmunotherapy of B-cell lymphoma with [131I]anti-B1 (anti-CD20) antibody. N Engl J Med. 1993; 329:459-65. Development of a practical regimen for outpatient therapy of lymphoma with RIT. [PubMed: 7687326]

48. Horning SJ, et al. Efficacy and safety of tositumomab and iodine-131 tositumomab (Bexxar) in Bcell lymphoma, progressive after rituximab. J Clin Oncol. 2005; 23:712-9. [PubMed: 15613695]

49. Goldenberg DM, Morschhauser F, Wegener WA. Veltuzumab (humanized anti-CD20 monoclonal antibody): characterization, current clinical results, and future prospects. Leuk Lymphoma. 2010; 51:747-55. [PubMed: 20214444]

50. Davis TA, et al. The radioisotope contributes significantly to the activity of radioimmunotherapy. Clin Cancer Res. 2004; 10:7792-8. Documentation of the role of radionuclides in anti-CD20 RIT. [PubMed: 15585610]

51. Fisher RI, et al. Tositumomab and iodine-131 tositumomab produces durable complete remissions in a subset of heavily pretreated patients with low-grade and transformed non-Hodgkin's lymphomas. J Clin Oncol. 2005; 23:7565-73. [PubMed: 16186600]

52. Bennett JM, et al. Assessment of treatment-related myelodysplastic syndromes and acute myeloid leukemia in patients with non-Hodgkin lymphoma treated with tositumomab and iodine ${ }^{131} \mathrm{I}$ tositumomab. Blood. 2005; 105:4576-82. [PubMed: 15731177]

53. Mones JV, et al. Dose-attenuated radioimmunotherapy with tositumomab and iodine 131 tositumomab in patients with recurrent non-Hodgkin's lymphoma (NHL) and extensive bone marrow involvement. Leuk Lymphoma. 2007; 48:342-8. [PubMed: 17325895]

54. Czuczman MS, et al. Treatment-related myelodysplastic syndrome and acute myelogenous leukemia in patients treated with ibritumomab tiuxetan radioimmunotherapy. J Clin Oncol. 2007; 25:4285-92. [PubMed: 17709799]

55. Sharkey RM, Press OW, Goldenberg DM. A re-examination of radioimmunotherapy in the treatment of non-Hodgkin lymphoma: prospects for dual-targeted antibody/radioantibody therapy. Blood. 2009; 113:3891-5. [PubMed: 19182204]

56. Johnson TA, Press OW. Synergistic cytotoxicity of iodine-131-anti-CD20 monoclonal antibodies and chemotherapy for treatment of B-cell lymphomas. Int J Cancer. 2000; 85:104-12. [PubMed: 10585592]

57. Gopal AK, et al. Myeloablative I-131-tositumomab with escalating doses of fludarabine and autologous hematopoietic transplantation for adults age $>/=60$ years with B cell lymphoma. Biol Blood Marrow Transplant. 2014; 20:770-5. [PubMed: 24530971]

58. Press OW, et al. A phase I/II trial of iodine-131-tositumomab (anti-CD20), etoposide, cyclophosphamide, and autologous stem cell transplantation for relapsed B-cell lymphomas. Blood. 2000; 96:2934-42. [PubMed: 11049969]

59. Witzig TE, et al. Anti-CD22 90Y-epratuzumab tetraxetan combined with anti-CD20 veltuzumab: a phase I study in patients with relapsed/refractory, aggressive non-Hodgkin lymphoma. Haematologica. 2014

60. Press OW, et al. Phase II trial of CHOP chemotherapy followed by tositumomab/iodine I-131 tositumomab for previously untreated follicular non-Hodgkin's lymphoma: five-year follow-up of Southwest Oncology Group Protocol S9911. J Clin Oncol. 2006; 24:4143-9. [PubMed: 16896003]

61. Leonard JP, et al. Abbreviated chemotherapy with fludarabine followed by tositumomab and iodine I 131 tositumomab for untreated follicular lymphoma. J Clin Oncol. 2005; 23:5696-704. [PubMed: 16110029]

62. Jacobs SA, et al. Phase II trial of short-course CHOP-R followed by 90Y-ibritumomab tiuxetan and extended rituximab in previously untreated follicular lymphoma. Clin Cancer Res. 2008; 14:7088-94. [PubMed: 18981007]

63. Zinzani PL, et al. A phase II trial of CHOP chemotherapy followed by yttrium 90 ibritumomab tiuxetan (Zevalin) for previously untreated elderly diffuse large B-cell lymphoma patients. Ann Oncol. 2008; 19:769-73. [PubMed: 18303033]

64. Zinzani PL, et al. Fludarabine and mitoxantrone followed by yttrium-90 ibritumomab tiuxetan in previously untreated patients with follicular non-Hodgkin lymphoma trial: a phase II nonrandomised trial (FLUMIZ). Lancet Oncol. 2008; 9:352-8. [PubMed: 18342572] 
65. Zinzani PL, et al. Phase II trial of short-course R-CHOP followed by 90Y-ibritumomab tiuxetan in previously untreated high-risk elderly diffuse large B-cell lymphoma patients. Clin Cancer Res. 2010; 16:3998-4004. [PubMed: 20542986]

66. Zinzani PL, et al. A phase 2 trial of fludarabine and mitoxantrone chemotherapy followed by yttrium-90 ibritumomab tiuxetan for patients with previously untreated, indolent, nonfollicular, non-Hodgkin lymphoma. Cancer. 2008; 112:856-62. [PubMed: 18189293]

67. Link BK, et al. Cyclophosphamide, vincristine, and prednisone followed by tositumomab and iodine-131-tositumomab in patients with untreated low-grade follicular lymphoma: eight-year follow-up of a multicenter phase II study. J Clin Oncol. 2010

68. Morschhauser F, et al. Phase III trial of consolidation therapy with yttrium-90-ibritumomab tiuxetan compared with no additional therapy after first remission in advanced follicular lymphoma. J Clin Oncol. 2008; 26:5156-64. [PubMed: 18854568]

69. Press OW, et al. Phase III randomized intergroup trial of CHOP plus rituximab compared with CHOP chemotherapy plus (131)iodine-tositumomab for previously untreated follicular nonHodgkin lymphoma: SWOG S0016. J Clin Oncol. 2013; 31:314-20. [PubMed: 23233710]

70. Husband JE, et al. Evaluation of the response to treatment of solid tumours - a consensus statement of the International Cancer Imaging Society. Br J Cancer. 2004; 90:2256-60. [PubMed: 15150551]

71. Schaefer NG, Ma J, Huang P, Buchanan J, Wahl RL. Radioimmunotherapy in non-Hodgkin lymphoma: opinions of U.S. medical oncologists and hematologists. J Nucl Med. 2010; 51:98794. [PubMed: 20484425]

72. Matthews DC, et al. Phase I study of (131)I-anti-CD45 antibody plus cyclophosphamide and total body irradiation for advanced acute leukemia and myelodysplastic syndrome. Blood. 1999; 94:1237-47. [PubMed: 10438711]

73. McDevitt MR, Finn RD, Ma D, Larson SM, Scheinberg DA. Preparation of alpha-emitting 213Bilabeled antibody constructs for clinical use. J Nucl Med. 1999; 40:1722-7. [PubMed: 10520715]

74. Rosen ST, et al. Radioimmunodetection and radioimmunotherapy of cutaneous T cell lymphomas using an 131I-labeled monoclonal antibody: an Illinois Cancer Council Study. J Clin Oncol. 1987; 5:562-73. [PubMed: 3549989]

75. Zhang M, et al. The anti-CD25 monoclonal antibody 7G7/B6, armed with the alpha-emitter 211At, provides effective radioimmunotherapy for a murine model of leukemia. Cancer Res. 2006; 66:8227-32. [PubMed: 16912202]

76. Gopal AK, Pagel JM, Fromm JR, Wilbur S, Press OW. 131I anti-CD45 radioimmunotherapy effectively targets and treats T-cell non-Hodgkin lymphoma. Blood. 2009; 113:5905-10. [PubMed: 19332764]

77. Dietlein M, et al. Development of anti-CD30 radioimmunoconstructs (RICs) for treatment of Hodgkin's lymphoma. Studies with cell lines and animal studies. Nuklearmedizin. 2010; 49:97105. [PubMed: 20126826]

78. Ocean AJ, et al. Fractionated radioimmunotherapy with (90) Y-clivatuzumab tetraxetan and lowdose gemcitabine is active in advanced pancreatic cancer: A phase 1 trial. Cancer. 2012; 118:5497-506. [PubMed: 22569804]

79. Reardon DA, et al. Salvage radioimmunotherapy with murine iodine-131-labeled antitenascin monoclonal antibody $81 \mathrm{C} 6$ for patients with recurrent primary and metastatic malignant brain tumors: phase II study results. J Clin Oncol. 2006; 24:115-22. [PubMed: 16382120]

80. Reardon DA, et al. A pilot study: 131I-antitenascin monoclonal antibody 81c6 to deliver a 44-Gy resection cavity boost. Neuro Oncol. 2008; 10:182-9. [PubMed: 18287339]

81. Zalutsky MR, et al. Clinical experience with alpha-particle-emitting At-211: treatment of recurrent brain tumor patients with At-211-labeled chimeric antitenascin monoclonal antibody 81C6. Journal of Nuclear Medicine. 2008; 49:30-38. [PubMed: 18077533]

82. Xu H, Cheung IY, Guo HF, Cheung NK. MicroRNA miR-29 modulates expression of immunoinhibitory molecule B7-H3: potential implications for immune based therapy of human solid tumors. Cancer Res. 2009; 69:6275-81. [PubMed: 19584290]

83. Spector R, Mock DM. Biotin transport and metabolism in the central nervous system. Neurochem Res. 1988; 13:213-9. [PubMed: 3386776]

Nat Rev Cancer. Author manuscript; available in PMC 2016 March 18. 
84. Davson, H.; Segal, MB. CRC Press; Boca Raton, FL: 1996. p. 489-523.

85. Goodwin DA, Meares CF, Osen M. Biological properties of biotin-chelate conjugates for pretargeted diagnosis and therapy with the avidin/biotin system. J Nucl Med. 1998; 39:1813-8. Initial biotin avidin for multi-step targeting. [PubMed: 9776294]

86. Rosebrough SF. Pharmacokinetics and biodistribution of radiolabeled avidin, streptavidin and biotin. Nucl Med Biol. 1993; 20:663-8. [PubMed: 8358353]

87. Paganelli G, et al. Three-step monoclonal antibody tumor targeting in carcinoembryonic antigenpositive patients. Cancer Res. 1991; 51:5960-6. [PubMed: 1933860]

88. Humm JL, Chin LM, Macklis RM. F(ab')2 fragments versus intact antibody—an isodose comparison [comment]. J Nucl Med. 1990; 31:1045-7. [PubMed: 2189961]

89. Sharkey RM, Goldenberg DM. Advances in radioimmunotherapy in the age of molecular engineering and pretargeting. Cancer Invest. 2006; 24:82-97. [PubMed: 16466997]

90. Goldenberg DM, Sharkey RM, Paganelli G, Barbet J, Chatal JF. Antibody pretargeting advances cancer radioimmunodetection and radioimmunotherapy. J Clin Oncol. 2006; 24:823-34. Novel forms of pre-targeting in RIT. [PubMed: 16380412]

91. Kenanova V, et al. Radioiodinated versus radiometal-labeled anti-carcinoembryonic antigen single-chain Fv-Fc antibody fragments: optimal pharmacokinetics for therapy. Cancer Res. 2007; 67:718-26. [PubMed: 17234783]

92. Larson SM, et al. Single chain antigen binding protein (sFv CC49): first human studies in colorectal carcinoma metastatic to liver. Cancer. 1997; 80:2458-68. [PubMed: 9406696]

93. Waldmann TA, et al. Radioimmunotherapy of interleukin-2R alpha-expressing adult T-cell leukemia with Yttrium-90-labeled anti-Tac. Blood. 1995; 86:4063-75. [PubMed: 7492762]

94. Hnatowich DJ, Virzi F, Rusckowski M. Investigations of avidin and biotin for imaging applications. J Nucl Med. 1987; 28:1294-302. [PubMed: 3612292]

95. Axworthy DB, et al. Cure of human carcinoma xenografts by a single dose of pretargeted yttrium-90 with negligible toxicity. Proc Natl Acad Sci U S A. 2000; 97:1802-7. Optimized regimen for streptavidin/biotin multi-step targeting of solid tumours, with excellent targeting in vivo with tumour-to-blood TI of approximately 70, for a reagent that was ultimately introduced into man. [PubMed: 10677537]

96. Schultz J, et al. A tetravalent single-chain antibody-streptavidin fusion protein for pretargeted lymphoma therapy. Cancer Res. 2000; 60:6663-9. [PubMed: 11118050]

97. Paganelli G, et al. Intraperitoneal radio-localization of tumors pre-targeted by biotinylated monoclonal antibodies. Int J Cancer. 1990; 45:1184-9. [PubMed: 2351490]

98. Goodwin DA, Meares CF. Advances in pretargeting biotechnology. Biotechnol Adv. 2001; 19:435-50. [PubMed: 14538068]

99. Zhang M, et al. Pretarget radiotherapy with an anti-CD25 antibody-streptavidin fusion protein was effective in therapy of leukemia/lymphoma xenografts. Proc Natl Acad Sci U S A. 2003; 100:1891-5. [PubMed: 12569172]

100. Press OW, et al. A comparative evaluation of conventional and pretargeted radioimmunotherapy of CD20-expressing lymphoma xenografts. Blood. 2001; 98:2535-2543. [PubMed: 11588052]

101. Pagel JM, et al. Comparison of a tetravalent single-chain antibody-streptavidin fusion protein and an antibody-streptavidin chemical conjugate for pretargeted anti-CD20 radioimmunotherapy of B-cell lymphomas. Blood. 2006; 108:328-36. [PubMed: 16556891]

102. Sharkey RM, et al. A universal pretargeting system for cancer detection and therapy using bispecific antibody. Cancer Res. 2003; 63:354-63. [PubMed: 12543788]

103. Barbet J, et al. Pretargeting with the affinity enhancement system for radioimmunotherapy. Cancer Biother Radiopharm. 1999; 14:153-66. [PubMed: 10850300]

104. Gautherot E, et al. Pretargeted radioimmunotherapy of human colorectal xenografts with bispecific antibody and 131I-labeled bivalent hapten. J Nucl Med. 2000; 41:480-7. [PubMed: 10716323]

105. Chang CH, Rossi EA, Goldenberg DM. The dock and lock method: a novel platform technology for building multivalent, multifunctional structures of defined composition with retained bioactivity. Clin Cancer Res. 2007; 13:5586s-5591s. [PubMed: 17875793] 
106. Rossi EA, et al. Stably tethered multifunctional structures of defined composition made by the dock and lock method for use in cancer targeting. Proc Natl Acad Sci U S A. 2006; 103:6841-6. [PubMed: 16636283]

107. Chmura AJ, Orton MS, Meares CF. Antibodies with infinite affinity. Proc Natl Acad Sci U S A. 2001; 98:8480-4. Multistep targeting with antibodies that bind convalently to tumour. [PubMed: 11447282]

108. Butlin NG, Meares CF. Antibodies with infinite affinity: origins and applications. Acc Chem Res. 2006; 39:780-7. [PubMed: 17042478]

109. Orcutt KD, et al. A modular IgG-scFv bispecific antibody topology. Protein Eng Des Sel. 2010; 23:221-8. Initial design for a DOTA-based PRIT. [PubMed: 20019028]

110. Chen $X$, et al. Synthesis and in vitro characterization of a dendrimer-MORF conjugate for amplification pretargeting. Bioconjug Chem. 2008; 19:1518-25. [PubMed: 18646837]

111. Liu X, Wang Y, Nakamura K, Kubo A, Hnatowich DJ. Cell studies of a three-component antisense MORF/tat/Herceptin nanoparticle designed for improved tumor delivery. Cancer Gene Ther. 2008; 15:126-32. [PubMed: 18084241]

112. Cheal SM, et al. Preclinical evaluation of multistep targeting of diasialoganglioside GD2 using an IgG-scFv bispecific antibody with high affinity for GD2 and DOTA metal complex. Mol Cancer Ther. 2014; 13:1803-12. [PubMed: 24944121]

113. Forero A, et al. Phase 1 trial of a novel anti-CD20 fusion protein in pretargeted radioimmunotherapy for B-cell non-Hodgkin lymphoma. Blood. 2004; 104:227-236. Initial human trials in lymphoma with multi-step targeting based on streptavidin/biotin binding. [PubMed: 14996706]

114. Forero-Torres A, et al. Pretargeted radioimmunotherapy (RIT) with a novel anti-TAG-72 fusion protein. Cancer Biother Radiopharm. 2005; 20:379-90. [PubMed: 16114986]

115. Knox SJ, et al. Phase II trial of yttrium-90-DOTA-biotin pretargeted by NR-LU-10 antibody/ streptavidin in patients with metastatic colon cancer. Clin Cancer Res. 2000; 6:406-14. [PubMed: 10690517]

116. Kraeber-Bodere F, et al. Pharmacokinetics and dosimetry studies for optimization of anticarcinoembryonic antigen $\mathrm{x}$ anti-hapten bispecific antibody-mediated pretargeting of Iodine-131labeled hapten in a phase I radioimmunotherapy trial. Clin Cancer Res. 2003; 9:3973S-81S. [PubMed: 14506196]

117. Aarts F, et al. Pretargeted radioimmunoscintigraphy in patients with primary colorectal cancer using a bispecific anticarcinoembryonic antigen CEA X anti-di-diethylenetriaminepentaacetic acid F(ab')2 antibody. Cancer. 2010; 116:1111-7. [PubMed: 20127959]

118. Vuillez JP, et al. Radioimmunotherapy of small cell lung carcinoma with the two-step method using a bispecific anti-carcinoembryonic antigen/anti-diethylenetriaminepentaacetic acid (DTPA) antibody and iodine-131 Di-DTPA hapten: results of a phase I/II trial. Clin Cancer Res. 1999; 5:3259s-3267s. [PubMed: 10541373]

119. Kraeber-Bodere F, et al. Radioimmunotherapy in medullary thyroid cancer using bispecific antibody and iodine 131-labeled bivalent hapten: preliminary results of a phase I/II clinical trial. Clin Cancer Res. 1999; 5:3190s-3198s. [PubMed: 10541363]

120. Grana C, et al. Pretargeted adjuvant radioimmunotherapy with yttrium-90-biotin in malignant glioma patients: a pilot study. Br J Cancer. 2002; 86:207-12. [PubMed: 11870507]

121. Walter RB, Press OW, Pagel JM. Pretargeted radioimmunotherapy for hematologic and other malignancies. Cancer Biother Radiopharm. 2010; 25:125-42. General review of the pitfalls and potential of PRIT. [PubMed: 20423225]

122. Emami B, et al. Tolerance of normal tissue to therapeutic irradiation. Int J Radiat Oncol Biol Phys. 1991; 21:109-22. [PubMed: 2032882]

123. Maxon HR, et al. Relation between effective radiation dose and outcome of radioiodine therapy for thyroid cancer. N Engl J Med. 1983; 309:937-41. [PubMed: 6621620]

124. Larson SM, et al. PET scanning of iodine-124-3F9 as an approach to tumor dosimetry during treatment planning for radioimmunotherapy in a child with neuroblastoma. J Nucl Med. 1992; 33:2020-3. Initial use of PET scanning for dosimetry in humans: initial theranostic application. [PubMed: 1432165] 
125. Kramer K, et al. Pharmacokinetics and acute toxicology of intraventricular 131 I-monoclonal antibody targeting disialoganglioside in non-human primates. J Neurooncol. 1997; 35:101-11. [PubMed: 9266446]

126. Dobrenkov K, Cheung NK. GD2-targeted immunotherapy and radioimmunotherapy. Semin Oncol. 2014; 41:589-612. [PubMed: 25440605]

127. Cheung NK, et al. Murine anti-GD2 monoclonal antibody 3F8 combined with granulocytemacrophage colony-stimulating factor and 13-cis-retinoic acid in high-risk patients with stage 4 neuroblastoma in first remission. J Clin Oncol. 2012; 30:3264-70. [PubMed: 22869886]

128. Cheung NK, et al. Single-chain Fv-streptavidin substantially improved therapeutic index in multistep targeting directed at disialoganglioside GD2. J Nucl Med. 2004; 45:867-77. [PubMed: 15136638]

129. Hainsworth JD, et al. Rituximab plus short-duration chemotherapy followed by Yttrium-90 Ibritumomab tiuxetan as first-line treatment for patients with follicular non-Hodgkin lymphoma: a phase II trial of the Sarah Cannon Oncology Research Consortium. Clin Lymphoma Myeloma. 2009; 9:223-8. [PubMed: 19525191]

130. Zinzani PL, et al. A phase II trial of short course fludarabine, mitoxantrone, rituximab followed by (9)(0)Y-ibritumomab tiuxetan in untreated intermediate/high-risk follicular lymphoma. Ann Oncol. 2012; 23:415-20. [PubMed: 21536660]

131. Morschhauser F, et al. 90Yttrium-ibritumomab tiuxetan consolidation of first remission in advanced-stage follicular non-Hodgkin lymphoma: updated results after a median follow-up of 7.3 years from the International, Randomized, Phase III First-LineIndolent trial. J Clin Oncol. 2013; 31:1977-83. [PubMed: 23547079]

132. Scheinberg DA, et al. A phase I trial of monoclonal antibody M195 in acute myelogenous leukemia: specific bone marrow targeting and internalization of radionuclide. J Clin Oncol. 1991; 9:478-90. [PubMed: 1999719]

133. Allen BJ, et al. Analysis of patient survival in a Phase I trial of systemic targeted alpha-therapy for metastatic melanoma. Immunotherapy. 2011; 3:1041-1050. [PubMed: 21913827]

134. Allen BJ, et al. Intralesional targeted alpha therapy for metastatic melanoma. Cancer Biology \& Therapy. 2005; 4:1318-1324. [PubMed: 16322682]

135. Raja C, et al. Interim analysis of oxicity and response in phase 1 trial of systemic targeted alpha therapy for metastatic melanoma. Cancer Biology \& Therapy. 2007; 6:846-852. [PubMed: 17495524]

\section{Biographies}

Nai-Kong V. Cheung received his M.D. and Ph.D. (Immunology) from Harvard Medical School. Following specialty training in Pediatric Hematology/Oncology at Stanford University, he became interested in the immunotherapy of cancer, developing monoclonal antibodies targeting tumor antigens in metastatic neuroblastoma, including antibody 3F8 against ganglioside GD2 and 8H9 against B7-H3. He holds the Enid A. Haupt Chair in Pediatric Oncology, heads the neuroblastoma program, and directs the Robert Steel Laboratory at Memorial Sloan Kettering Cancer Center. There he established an active translational program to explore novel genetically engineered antibodies and bring them to pediatric patients. Dr. Cheung's lab website: http://www.mskcc.org/mskcc/html/55349.cfm

Oliver W. Press, M.D., Ph.D. holds the Dr. Penny E. Peterson Memorial Chair for Lymphoma Research at the Fred Hutchinson Cancer Research Center (FHCRC) and is a Professor of Medicine and Bioengineering at the University of Washington. Dr. Press is also currently the Acting Director of the Clinical Research Division at FHCRC. His research focuses on the investigation of novel immunotherapeutic approaches for the treatment of 
haematological malignancies, including lymphoma, leukaemia and multiple myeloma. Dr. Press's lab website: http://research.fhcrc.org/press/en.html

Dr. Carrasquillo is an Attending physician in the Molecular Imaging and Therapy Service, Member and Head of the Radionuclide therapy section, and Co-Director of Targeted Radioimmunotherapy and Theranostics of the Ludwig Center for Cancer Immunotherapy at Memorial Sloan Kettering Cancer Center. He is an expert on molecular imaging, targeted radiodiagnosis, and therapy using monoclonal antibodies.

Dr. Larson is an Attending physician in the Molecular Imaging and Therapy Service at Memorial Sloan Kettering Cancer Center, Member and Lab Head in the Molecular Pharmacology and Chemistry program of Sloan Kettering Institute (SKI), Director of Targeted Radioimmunotherapy and Theranostics of the Ludwig Center for Cancer Immunotherapy (LCCI), and Co-leader of the Imaging and Radiation Sciences Bridge Program. Dr. Larson is an expert on molecular imaging, targeted radio diagnosis, and therapy using monoclonal antibodies. Dr. Larson's lab website: http://www.mskcc.org/ research/lab/steven-larson 


\section{AT A GLANCE}

- Antibodies with practical healthcare applications are being introduced into modern medicine at a rapid pace by academic laboratories and industry. Therapeutic applications of these biologics are becoming increasingly important for cancer, either by promoting the body's own defense against the tumour or as a carrier for immunotoxins, drugs, or radiation.

- Radioimmunotherapy, the subject of this Review, exploits the immune protein as a carrier for radioactive isotopes, tracers, or targeted therapeutics. The radioantibody is introduced into the blood or a body cavity such as the peritoneum, pleura, or intrathecal space, and is carried to its natural target or antigen-binding site on the tumour cell by blood flow, diffusion, or bulk flow of fluid.

- Cancer cells naturally produce cancer-associated biological moleculesadaptive features of malignant change that are suitable as antigenic binding sites due to their relatively high abundance in comparison to normal tissues. These cancer-associated antigens may be located in the membrane, cytoplasm, or organelles, including the nucleus. Typical concentrations of target antigens are in the nanomolar to low micromolar range.

- Cancer-selective antibodies and related immunoproteins are particularly well suited for conjugation with radioisotopes, for the purpose of detection or targeted radiotherapy. As a rule of thumb, the concentration of antibody at the binding site should approximate but not exceed the concentration of antigen, i.e., the nanomolar range, and this amount of carrier is enormous relative to the required concentrations of attached radioisotopes for detection or therapy. This is because radioisotopes are among the most energetic moieties known, and this energy can be used for imaging or radiotherapy when attached to antibodies, in the femto- to pico-molar range. 


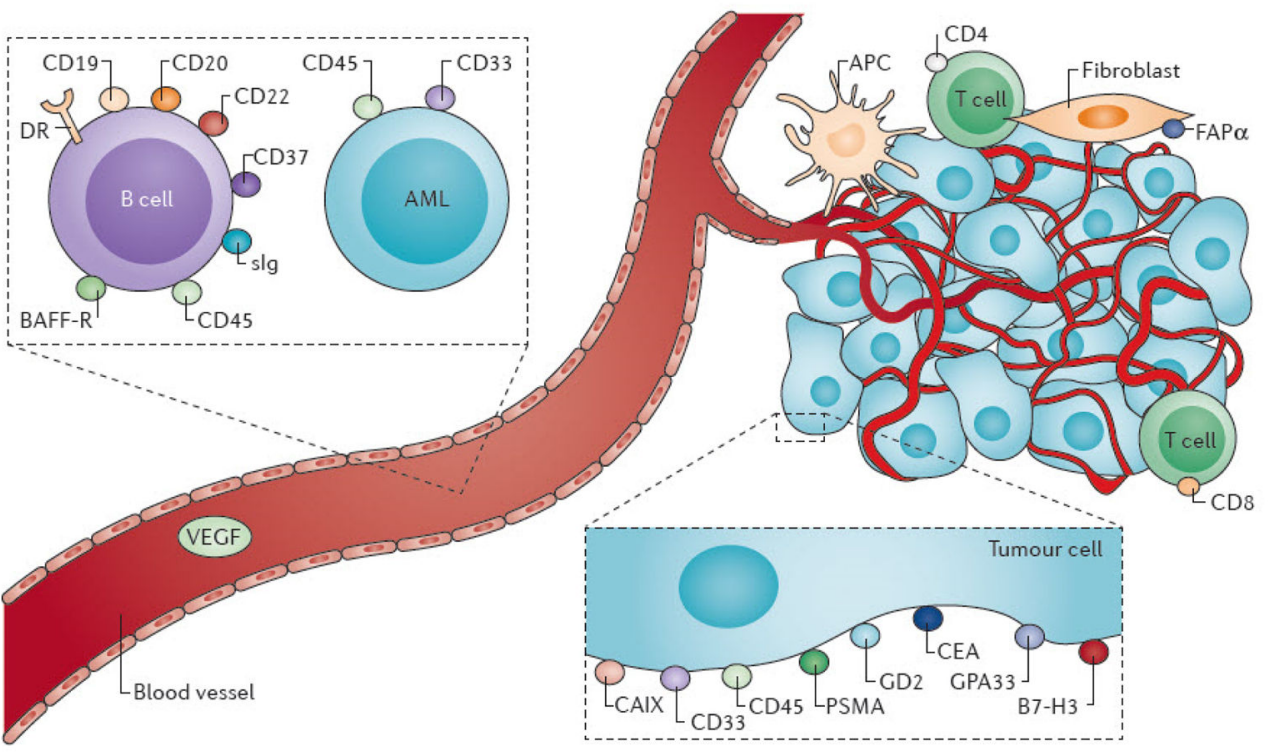

Figure 1. Target antigens for radioimmunotherapy

Target antigens for radioimmunotherapy (RIT) are most commonly accessible antigens on the cell surface of the neoplastic or stromal cell, and less commonly molecules that may be abundantly produced in the tumour environment. The simple case is targeting antigens on myeloid cells, and to a certain extent lymphomas, which are freely circulating in the blood and bone marrow. Radiolabeled antibody therapy of B-cell lymphoma include the receptor for B-cell activating factor (BAFF-R), class II histocompatibility antigens (HLA-DR), surface immunoglobulin (sIg), and cluster designation antigens CD19, CD20, CD22, CD37, and CD45. Target surface antigens for RIT of myeloid leukaemias include CD33 and CD45. For the solid tumours, there is also induction of stroma, vascular, and inflammatory cell components; RIT in principle can be applied to any one of these components (for example, to fibroblast activation protein-a (FAPa)), and commonly used cancer cell membrane targets include: carcinoembryonic antigen (CEA), prostate-specific membrane antigen (PSMA), GD2 ganglioside antigen (GD2) and carbonic anhydrase IX. 


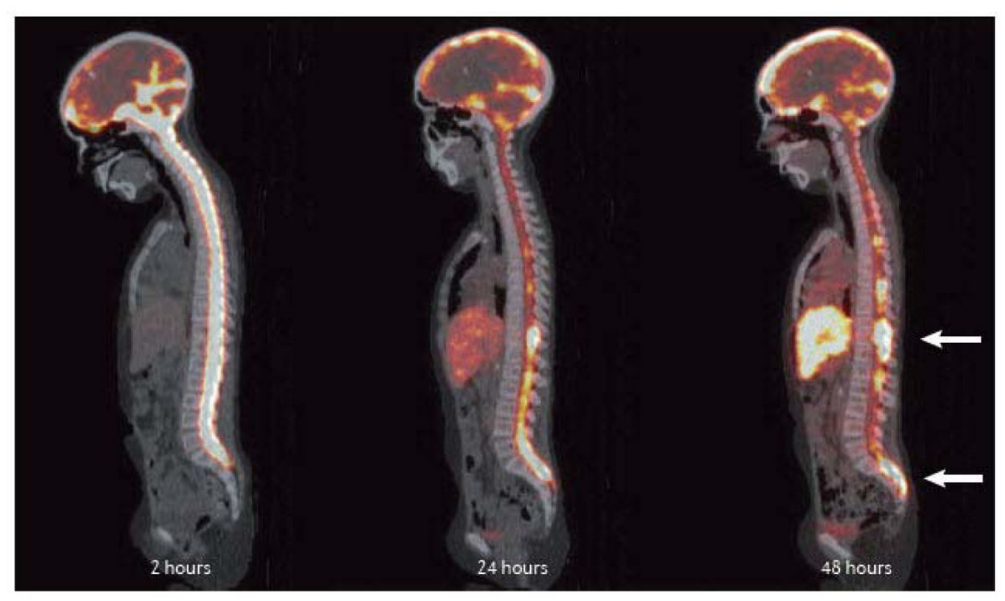

Figure 2. Intrathecal RIT imaged quantitatively with PET imaging, using ${ }^{124}$ I-8H9 antibody Images illustrate localization to leptomeningeal tumour of the radioactivity over the course of 72 hours. (All images shown are sagittal images through the intrathecal space).

Immediately after intrathecal injection via an Ommaya Reservoir [G], a two-hour image shows complete filling of the intrathecal space, with distribution throughout the CSF and progressive clearance at 24 and 48 hours, except at the tumour site. At 48 hours, there is focal uptake at tumour sites evident in the thoracic and lumbar spine (arrows). 


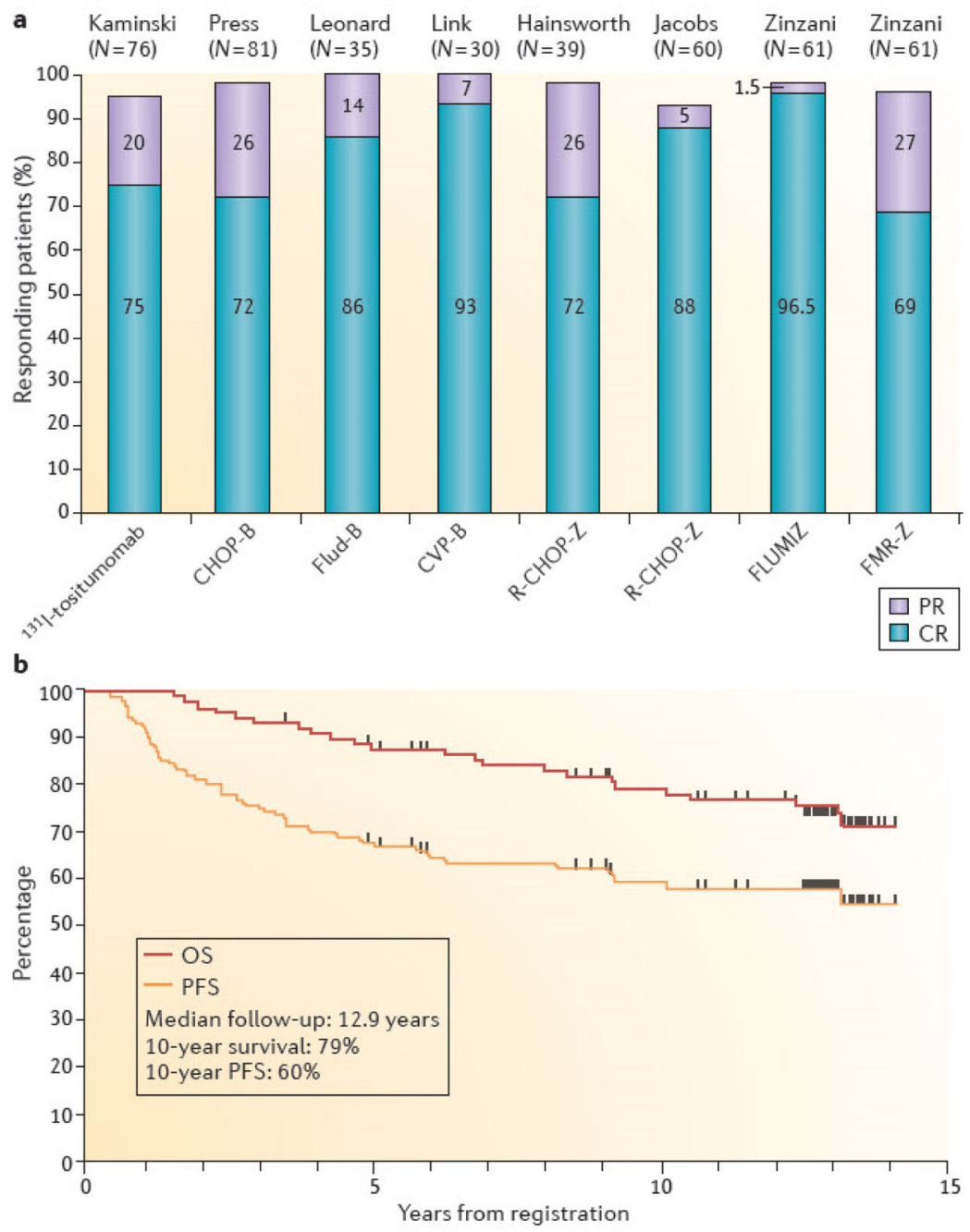

Figure 3. Results of selected trials of radioimmunotherapy as part of front-line therapy for follicular lymphoma

(A) Overall response rates, partial remission rates (purple), and complete remission rates (blue) are indicated for eight studies utilizing: ${ }^{131}$ I-tositumomab alone ${ }^{3}$; cyclophosphamide, doxorubicin, vincristine, and prednisone followed by ${ }^{131}$ I-tositumomab (CHOP-B $)^{60}$; fludarabine followed by ${ }^{131}$ I-tositumomab (Flud-B) ${ }^{61}$; cyclophosphamide, vincristine, and prednisone followed by ${ }^{131}$ I-tositumomab (CVP-B $)^{67}$; rituximab plus CHOP followed by ${ }^{90} \mathrm{Y}$-ibritumomab tiuxetan (R-CHOP-Z) ${ }^{129}$; fludarabine plus mitoxantrone followed by ${ }^{90} \mathrm{Y}$-ibritumomab tiuxetan (FLUM IZ) ${ }^{64}$; or fludarabine, mitoxantrone, rituximab, and zevalin followed by ${ }^{90} \mathrm{Y}$-ibritumomab tiuxetan $(\mathrm{FMR}-\mathrm{Z}){ }^{130}$. Data are graphed from the published studies. (B) Progression-free and overall survival of 90 eligible patients with advanced Follicular Non-Hodgkin's Lymphoma treated with six cycles of CHOP chemotherapy followed by tositumomab/ ${ }^{131}$ I-tositumomab on SWOG protocol S9911. 

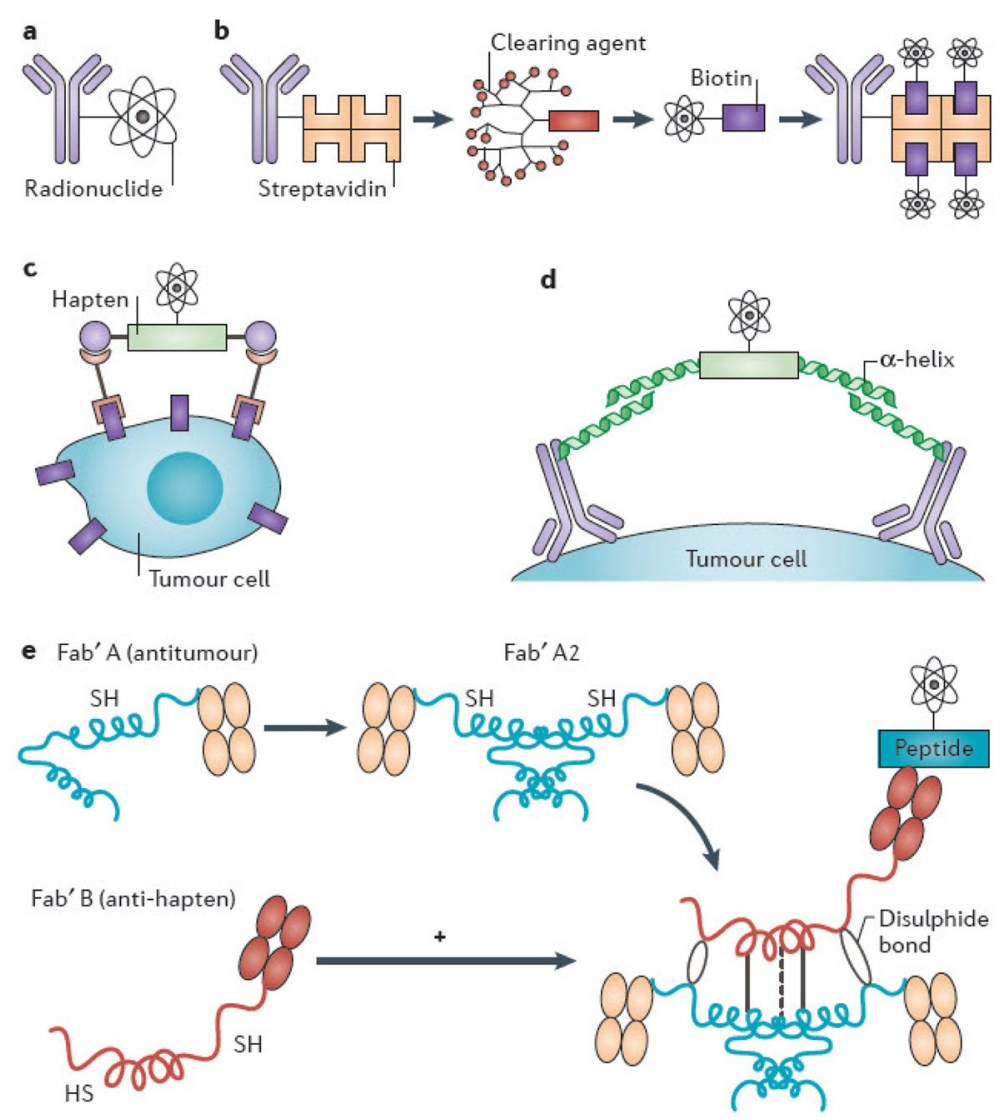

Figure 4. Schemas for conventional and pretargeted radioimmunotherapy

(A) Conventional single-step radioimmunotherapy (RIT), with monoclonal antibody conjugated directly to radionuclide. (B) Multi-step pretargeted RIT (PRIT) using antibodystreptavidin (Ab-SA) conjugates, followed by radiolabeled DOTA-biotin. The tetrameric streptavidin molecule can bind four radio-DOTA-biotin moieties, amplifying tumourtargeted radioactivity. The 16-merous, $\mathrm{N}$-acetylgalactose-containing "clearing agent" removes excess Ab-SA conjugate from circulation via hepatic asialoglycoprotein receptors prior to systemic delivery of radio-DOTA-biotin, improving tumour-to-normal organ ratios of absorbed radioactivity. (C) Bispecific antibody pretargeting for RIT using radiolabeled bivalent haptens and "affinity enhancement system." Another PRIT strategy employs bispecific antibodies recognizing both tumour-associated cell surface antigen and radiolabeled bivalent hapten (e.g., histamine-succinyl-glycine [HSG]), which facilitates cooperative binding by linking two bispecific Abs together on the cell surface. (D) Modular IgG-scFv bispecific PRIT. Disulfide-stabilized $\mathrm{scFv}$ with ultra-high affinity for radiometal DOTA fuses to C-terminus of an IgG light chain to create an IgG-scFv bifunctional antibody, targeting a cancer-associated antigen (e.g., CD20, CEA). ScFv (C825) is affinitymatured by directed evolution/yeast surface display to produce 1,000 -fold improved affinity for biotinylated DOTA-yttrium compared to parent antibody (2D12.5). (E) Bispecific antibody pretargeting using "dock and lock" technology with self-assembling protein kinase-A domains ${ }^{105,106}$. A clever modification of bispecific antibody targeting approach uses molecularly engineered "dimerization and docking domains" containing self- 
assembling protein kinase-A motifs with engineered cysteine residues. Upon mixing, two anti-tumour Fab fragments and one anti-hapten Fab fragment spontaneously associate, leading to "locking" of the fragments into a covalent trivalent complex. 


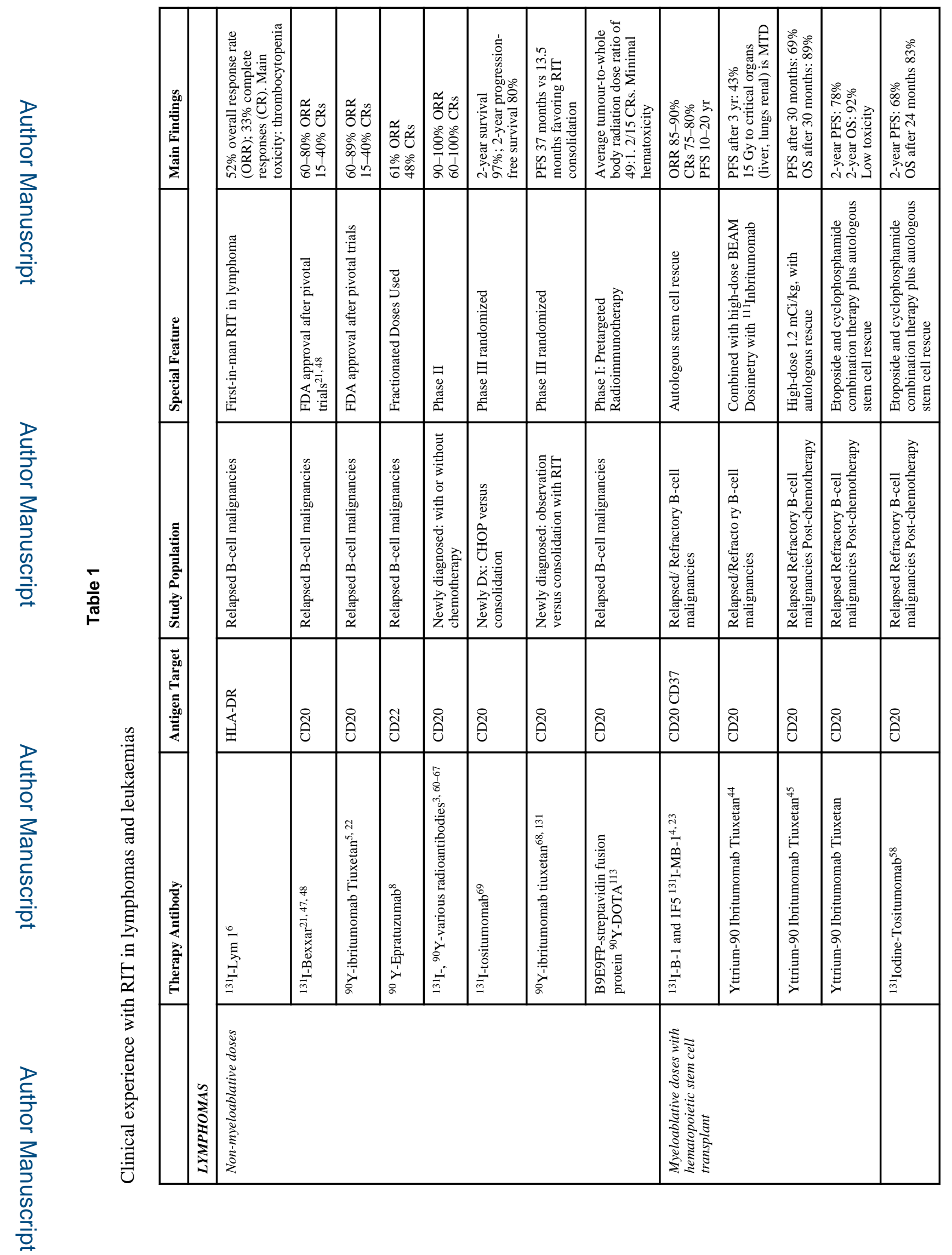

Nat Rev Cancer. Author manuscript; available in PMC 2016 March 18. 


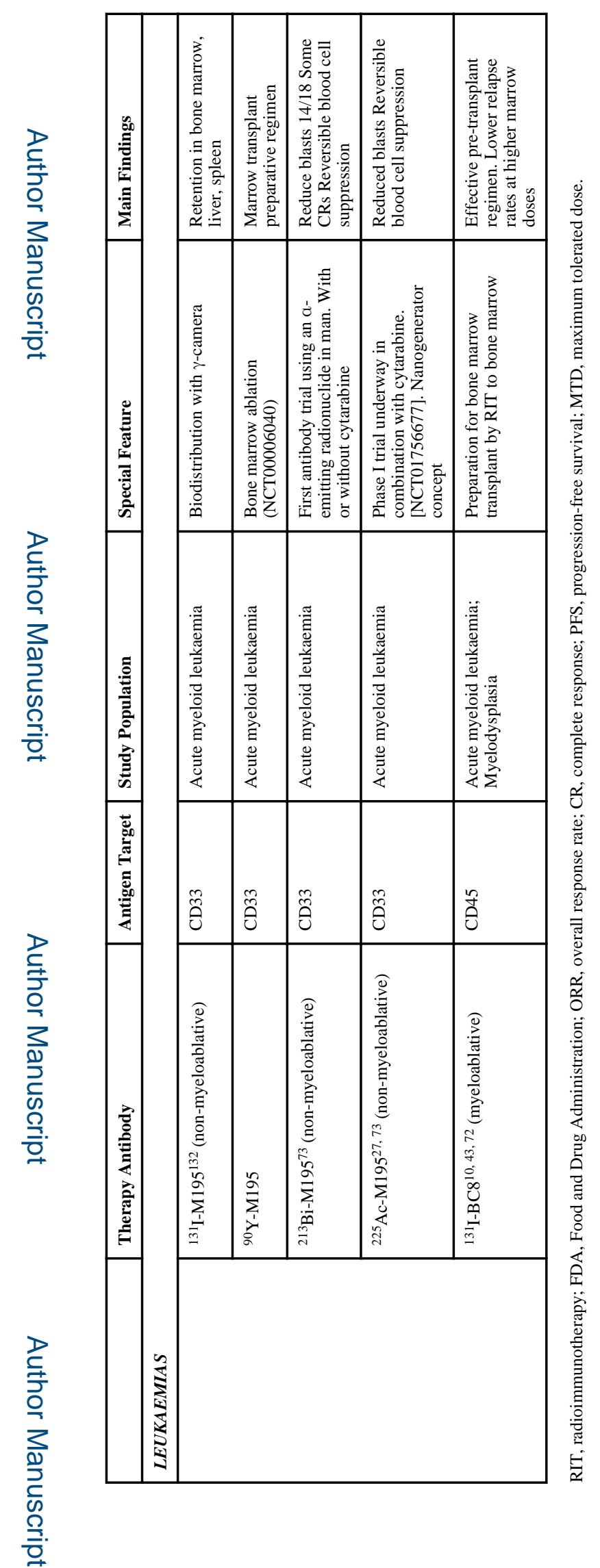

Nat Rev Cancer. Author manuscript; available in PMC 2016 March 18. 


\section{Table 2}

Alpha emitters in solid tumours

\begin{tabular}{|l|l|l|l|l|}
\hline Therapy Antibody & Antigen Target & Study Population & Special Feature & Main Findings \\
\hline${ }^{213} \mathrm{Bi}-9.2 .27^{133}$ & $\begin{array}{l}\text { Glial antigen 2 } \\
\text { (NG2) }\end{array}$ & $\begin{array}{l}\text { Stage IV or in transit } \\
\text { melanoma }\end{array}$ & $\begin{array}{l}\text { Long-term evaluation of } \\
\text { response? }\end{array}$ & $10 \%$ PR, 8\% SD, no MTD \\
\hline${ }^{213} \mathrm{Bi}-9.2 .27^{134}$ & $\begin{array}{l}\text { Glial antigen 2 } \\
\text { (NG2) }\end{array}$ & $\begin{array}{l}\text { Stage IV or in transit } \\
\text { melanoma }\end{array}$ & First-in-man direct injection & $\begin{array}{l}\text { Anti-tumour effect at 600 } \\
\text { microcurie. Safe, no MTD, } \\
\text { activity administered 150 to } \\
1350 \text { microCi }\end{array}$ \\
\hline${ }^{211} \mathrm{At}-\mathrm{ch} 81 \mathrm{C}^{81}$ & Tenascin & Primary brain tumours & $\begin{array}{l}18 \text { pt. 71-347 MBq post- } \\
\text { resection, delivery into surgically } \\
\text { created resection cavity }\end{array}$ & $\begin{array}{l}\text { No MTD achieved, no DLT. } \\
\text { No hematologic }>\text { grade 2. } \\
\text { Limited neurotoxicity. } \\
\text { Determined biodistribution. } \\
\text { Median survival 54 weeks for } \\
\text { GBM and 52 weeks for AA } \\
\text { and 116 weeks for OD, 2 of } \\
14 \text { GBM survived } ~ 3 \text { years. } \\
\text { Proof-of-concept regional } \\
\text { targeted radiotherapy with }\end{array}$ \\
\hline${ }^{213} \mathrm{Bi} 9.2 .27^{135}$ & $\begin{array}{l}\text { Glial antigen 2 } \\
\text { (NG2) }\end{array}$ & $\begin{array}{l}\text { 22 patients with stage IV } \\
\text { melanoma }\end{array}$ & $\begin{array}{l}\text { Phase I dose escalation. 1.5 to } \\
25.6 \text { mCi }\end{array}$ & $\begin{array}{l}211 \text { At. Well tolerated; no } \\
\text { DLT. 14\% PR, 50\% SD. }\end{array}$ \\
\hline
\end{tabular}

PR, partial remission; SD, standard deviation; MTD, maximum tolerated dose; DLT, dose-limiting toxicity; GBM, glioblastoma; AA, anaplastic astrocytoma; OD, oligodendroglioma. 